\title{
Bacterial Vaginosis
}

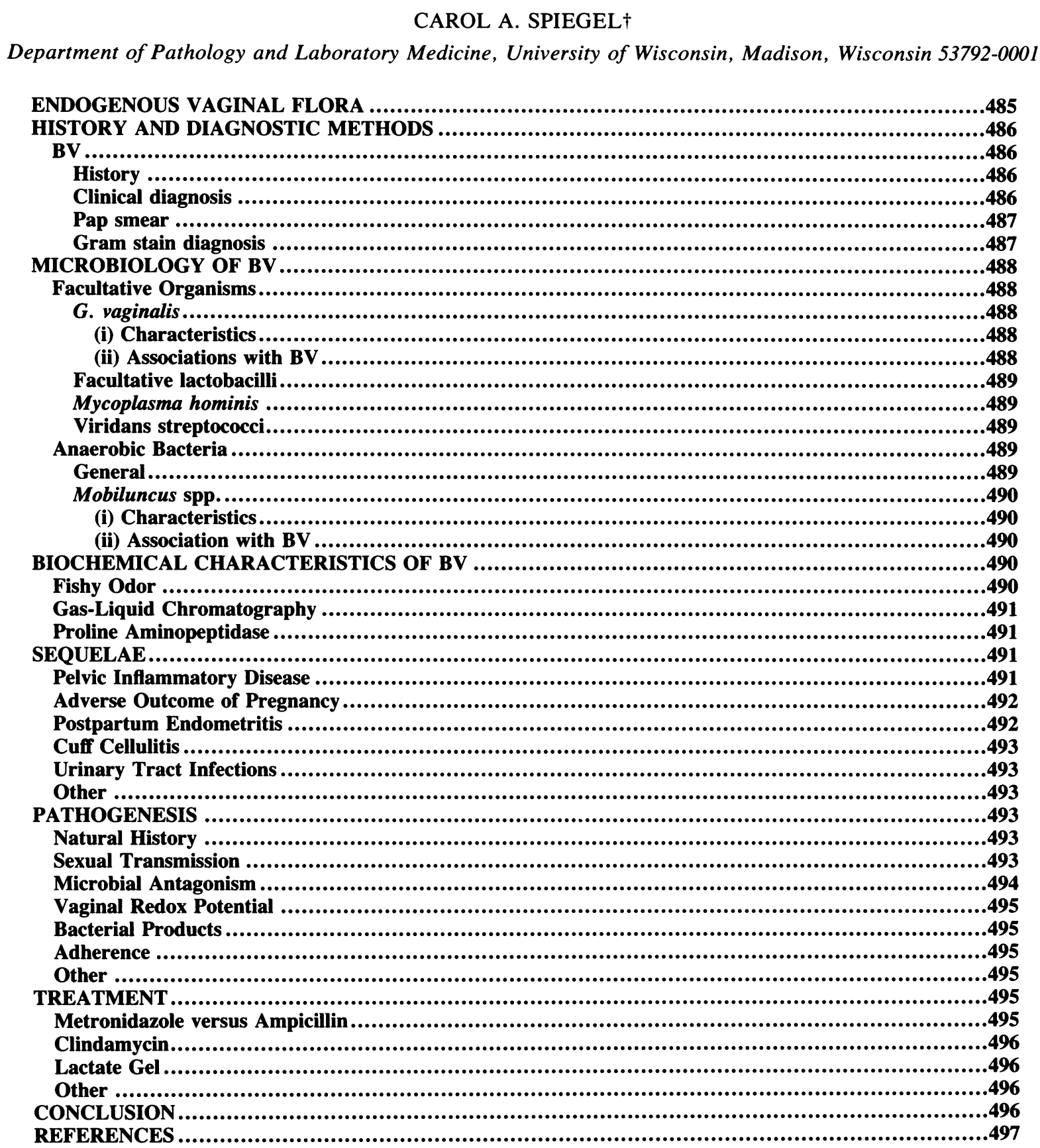

\section{ENDOGENOUS VAGINAL FLORA}

The vaginal flora has been characterized for premenarcheal girls $(67,68)$ and postmenarcheal $(9,10,101,119$, 142-144, 170, 207), pregnant (119), and postmenopausal

† Present address: University of Wisconsin Hospital and Clinics, 600 Highland Ave., A4/204 CSC, Madison, WI 53792-0001.
$(114,144,207)$ women. Other studies have characterized cervical flora $(55,56,135,209)$. These studies have recently been reviewed by Ison (94) and Hill et al. (73). Site and methods of sample collection, quality of anaerobic microbiology, definition of a healthy vagina, consideration of time in the menstrual cycle, sexual history, and contraceptive method used, all of which may affect the composition of the flora, vary among these studies.

The vaginal flora is greatly influenced by estrogens. In utero, the vagina of the fetus is microbiologically sterile. 
Organisms are first acquired from the hands of care givers and from the infant's feces. For the first 6 weeks of life, maternal estrogens are present in the vaginal epithelium, providing it with the morphology and microbiology of the adult vagina; i.e., facultative lactobacilli predominate $(23$, 108). After the estrogens have been metabolized, the flora contains skin organisms, e.g., coagulase-negative staphylococci, and fecal organisms, e.g., Escherichia coli. After menarche, the facultative microfiora of the healthy vagina is dominated by lactobacilli and diphtheroidal forms, which include Gardnerella vaginalis. Other gram-positive organisms include coagulase-negative staphylococci and alphaand nonhemolytic streptococci. Gram-negative rods are less common. Most women are also colonized by anaerobic organisms including but not limited to lactobacilli, peptostreptococci, Prevotella bivia, Prevotella disiens, other Prevotella spp. (175) and Porphyromonas spp. (174) (formerly saccharolytic and asaccharolytic black-pigmented Bacteroides spp., respectively), and Mycoplasma spp. The effects of the menstrual cycle and pregnancy on the vaginal flora have been reviewed recently (94). After menopause, facultative lactobacilli can be cultured from $65 \%$ of women (114), but they do not predominate on Gram-stained smears (188).

\section{HISTORY AND DIAGNOSTIC METHODS}

Vaginitis in premenarcheal girls is not common and may be due to yeast, Neisseria gonorrhoeae, pinworm, Shigella species, Streptococcus pyogenes, or bacterial vaginosis (BV) $(108,163)$. Abnormal discharge is a frequent complaint of women of reproductive age seeking gynecologic care, and evidence of vaginitis can be found in up to one-third of gynecology patients $(2,52)$. The three main categories of vaginitis are Trichomonas vaginalis vaginitis, yeast vaginitis, and BV. Methods for laboratory diagnosis of these have been summarized recently (193). BV is the most common of these three, accounting for 40 to $50 \%$ of all cases $(7,52)$. Mixed infections commonly occur, dictating that all three be sought in symptomatic patients.

\section{BV}

History. The syndrome now known as BV has undergone several name changes since the mid-1950s as we have acquired more knowledge of the syndrome and its associated flora. The name nonspecific vaginitis was originally used to distinguish this syndrome from the specific vaginitides associated with $T$. vaginalis and yeasts. When Gardner and Dukes reported that Haemophilus vaginalis (now G. vaginalis) was the etiologic agent of $\mathrm{BV}$, they changed the name of the syndrome accordingly (52). The term vaginosis was introduced to indicate that, in BV, unlike the specific vaginitides, there is an increased discharge without significant inflammation, as indicated by a relative absence of polymorphonuclear leukocytes (82). The term bacterial vaginosis was adopted to indicate that bacteria rather than fungi or parasites apparently cause this syndrome, but that the identities of these bacteria have not been fully delineated. Because much of the vaginosis-associated flora is anaerobic, the term anaerobic vaginosis has been suggested (16). Most recently, the name vaginal bacteriosis has been recommended as being grammatically correct $(74,93,186)$. In this review, current convention will be maintained and the syndrome will be referred to as BV.

Descriptions of vaginal flora in women with a syndrome consistent with what we now call BV were published before the turn of the century (112) and again in the early 1900s (172). Changes from a clean, or "grade I," lactobacillusdominated flora to an unclean, "grade III,' flora composed of multiple organisms including vibrios but without lactobacilli were discussed in the 1920 s and 1930 s $(35,172,226)$, but no specific agents were associated with these changes.

Clinical diagnosis. Until the 1950 s, women with a vaginal discharge who had neither detectable yeast cells nor $T$. vaginalis were given a diagnosis of nonspecific vaginitis, that is, a diagnosis by exclusion. In 1955, Gardner and Dukes (52) provided a clinical characterization of a syndrome they termed $H$. vaginalis vaginitis. They described the discharge as being thin, grey, and homogeneous, with a tendency to adhere to the vaginal walls rather than pool in the posterior fornix. The $\mathrm{pH}$ of the discharge was higher (4.5 to 6.0) than that in normal controls (4.0 to 4.7) but usually not as high as in patients with trichomoniasis (5.0 to 6.0), and it emitted a foul odor. They also described the presence on wet mount of "clue cells," i.e., vaginal epithelial cells so coated with coccobacillary organisms that the cell borders were obscured. Pheifer et al. (149) noted that a "fishy" odor was emitted when vaginal fluid from a woman with BV was exposed to $10 \%$ potassium hydroxide. In a study in which 311 consecutive women were evaluated for the presence of these criteria, Amsel et al. (2) proposed that a clinical diagnosis of $\mathrm{BV}$ should require the presence of three of the following signs: (i) vaginal fluid with a $\mathrm{pH}$ of $>4.5$, (ii) homogeneous adherent discharge, (iii) fishy odor on addition of $10 \%$ potassium hydroxide to the discharge, and (iv) clue cells on saline wet mount. This is the accepted standard set of criteria used for clinical diagnosis of BV. Modifications to these criteria have been suggested. Eschenbach et al. (49) showed that clue cells are a more specific indicator of BV when they represent $20 \%$ of the epithelial cells. Krohn et al. (110) showed that, in pregnant women, homogeneous discharge was not independently related to BV. Thomason et al. (210) also found homogeneous discharge to be of little value in diagnosing $\mathrm{BV}$ and recommended that the presence of clue cells and fishy odor be used for diagnosis. Cristiano et al. (32) recommended that, when three tests are performed (either a test for fishy odor, a wet mount for clue cells, and a direct Gram stain or a test for fishy odor, a wet mount for clue cells, and a test to determine whether the $\mathrm{pH}$ is $>4.5$ ), the presence of two of the criteria can be used for diagnosis of BV.

Theoretically, three of the four determinations used in the clinical diagnosis of BV can be made in the laboratory, i.e., fishy odor, $\mathrm{pH}$, and clue cells. According to previously published data (2), when vaginal fluid on swabs is sent to the laboratory, a diagnosis of BV can be made when two or more signs are present (sensitivity, $100 \%$; specificity, $98 \%$; positive predictive value, $91 \%$; negative predictive value, $100 \%$ ). No actual evaluations of this procedure have been published.

In one study, patient symptoms as well as signs were determined (2). Seventy-seven (32\%) of 242 women with normal vaginal exams complained of discharge, odor, or irritation, while $37(54 \%)$ of 69 women with clinical BV reported none of these symptoms. Similar observations had been made previously (52). These data indicate that asymptomatic $\mathrm{BV}$ is common and that patient symptoms cannot be used in making a diagnosis of BV. It should be noted that treatment of women with asymptomatic BV is not currently recommended (121).

To make sense of the literature, the standard method for 
TABLE 1. Summary of articles evaluating Gram strain diagnosis of $\mathbf{B V}^{a}$

\begin{tabular}{|c|c|c|c|c|c|c|}
\hline $\begin{array}{l}\text { Population } \\
\qquad(n)\end{array}$ & $\begin{array}{l}\text { Means of } \\
\text { diagnosis }\end{array}$ & $\begin{array}{c}\text { Sensitivity } \\
(\%)\end{array}$ & $\begin{array}{c}\text { Specificity } \\
(\%)\end{array}$ & $\begin{array}{l}\text { PPV } \\
(\%)\end{array}$ & $\begin{array}{l}\text { NPV } \\
(\%)\end{array}$ & Reference \\
\hline Student health clinic (60) & Clinical & 100 & 100 & & & 189 \\
\hline \multirow[t]{3}{*}{ STD clinic (640) } & Clinical & 97 & 79 & 69 & 98 & 49 \\
\hline & $20 \%$ clue cells & 80 & 95 & 93 & 85 & \\
\hline & Any clue cells & 93 & 85 & 80 & 95 & \\
\hline OB-GYN clinic $(500)$ & Clinical & 97 & 66 & 57 & 98 & 210 \\
\hline Pregnant women (593) & Clinical & 62 & 95 & 76 & 86 & 110 \\
\hline
\end{tabular}

a PPV, positive predictive value; NPV, negative predictive value; STD, sexually transmitted disease; OB-GYN, obstetrics and gynecology. See text for methods.

clinical diagnosis of BV must be used when evaluating new diagnostic tests or studying the microbiology, epidemiology, sequelae, or therapy of $\mathrm{BV}$.

Pap smear. Cytologists commonly report the presence of clue cells as an incidental finding in endocervical smears. Two studies have been published examining the utility of the Papanicolaou (Pap) smear for diagnosis of BV $(156,171)$. In one study (156), the Pap smear was apparently performed on vaginal fluid, not a cervical scraping, and so is not a valid evaluation of the method as it is used by clinicians. In the other study (171), a Pap smear of the ecto- and endocervix was compared with a Gram stain of the same specimen, culture of the ectocervix for $G$. vaginalis and Mobiluncus species, and clinical diagnosis based on fishy odor and wet mount for clue cells. The bacterial flora on the Pap smears was categorized as a large bacillus pattern, an anaerobic pattern with or without curved rods or a predominance of Gardnerella spp., or a scanty pattern. The data are difficult to interpret because the standard method for diagnosis of BV was not used. In addition, the composition of the cervical flora of women with BV has not been examined by either culture or Gram stain. Assumptions about their similarity should not be made (9). The presence of clue cells on the Pap smears correlated very poorly with detection of clue cells on vaginal fluid wet mount, indicating that the presence of the former should not be used to diagnose BV. While the Gram stain categories used in this study may be appropriate, their correlation with BV requires further examination.

Gram stain diagnosis. Microscopic changes in vaginal flora have long been associated with alterations in vaginal health $(92,172,185,226)$. Dunkelberg (40) was the first to evaluate the Gram stain for diagnosis of BV by using it to detect $G$. vaginalis. This work was done before the standardized criteria for diagnosis of BV had been developed, was based solely on the presence of small gram-negative bacilli, and was performed with standard Gram stain reagents, including a safranin counterstain. A standardized method for use of the direct Gram stain for diagnosis of BV has been described elsewhere (189). Slides are stained with the Kopeloff modification of the Gram stain, and, in addition, basic fuchsin is used as the counterstain. Microbial morphotypes are quantitated under oil immersion $(\times 1,000)$ as $1+(<1$ per field $), 2+$ ( 1 to 5 per field), $3+(6$ to 30 per field $)$, or $4+(>30$ per field $)$. Large gram-positive bacilli are called the Lactobacillus morphotype, and smaller gram-variable bacilli are called the Gardnerella morphotype. Other organisms are categorized by morphology only, e.g., gram-negative bacilli, curved rods, gram-positive cocci in chains, and fusiforms. When the Lactobacillus morphotype is present alone or in combination only with the Gardnerella morphotype, the smear is interpreted as normal. When a more mixed flora, including not only the Gardnerella morphotype but also other gram- negative and gram-positive bacteria such as curved rods, gram-negative rods, fusiforms, and gram-positive cocci, is present and when the Lactobacillus morphotype is absent or is present only in low numbers $(1$ to $2+)$, the smear is interpreted as consistent with BV. The presence of morphotypes other than the Lactobacillus or Gardnerella morphotype is considered abnormal, regardless of quantity.

In its original description, this method was compared retrospectively with a clinical diagnosis of $\mathrm{BV}$ (2) and was accurate in 25 of 25 college women with BV and in 35 of 35 women without BV. The Gram stain method for diagnosis of BV has since been evaluated by other authors in various settings (Table 1). Eschenbach et al. (49) evaluated the Gram stain method in a sexually transmitted diseases clinic, using a pH of $>4.7$ and $20 \%$ clue cells as two of the four criteria for diagnosis of BV. These authors also compared Gram stain diagnosis with the presence of $20 \%$ clue cells only and with the presence of any clue cells, the latter being a common method for diagnosis of $\mathrm{BV}$ in clinical practice. In the evaluation of Thomason et al. (210), Gram stain criteria were changed to include as abnormal those slides with a mixed flora exceeding the number of lactobacillus morphotypes, even when $\geq 3+$ lactobacilli per field were present. In a study of pregnant patients by Krohn et al. (110), the criteria were modified by specifying the number of bacterial cells of other morphotypes, e.g., gram-positive cocci, small gramnegative rods, curved gram-variable rods, or fusiforms, that must be present in order to interpret the smear as being consistent with $\mathrm{BV}$.

The reproducibility of interpretation of Gram-stained smears has been evaluated recently (127). Eighty consecutive vaginal swabs from 80 patients were used. Gram-stained slides were presented to three experienced microbiology technologists, each of whom interpreted 80 original slides, 80 duplicate slides prepared from the same specimen, and the 80 original slides examined a second time. The technologists were unaware of when they were reading a slide for the second time. Data were evaluated by using the weighted kappa statistic. With a kappa value of 1.0 being perfect agreement, calculated kappa values of $\leq 0.40$ reflect fair or poor reproducibility, those of $>0.41$ and $>0.80$ indicate moderate to substantial agreement, and those of $\geq 0.81$ reflect almost perfect agreement. Intraobserver agreement on the quantity of Lactobacillus and Gardnerella morphotypes and diagnosis of $\mathrm{BV}$ were high (0.772 to 1.000). Interobserver agreement was also high for detection of Lactobacillus morphotype and clue cells $(0.735$ to 0.869$)$, but decreased slightly for BV $(0.656$ to 0.800$)$.

In a more recent study, a standardized method for interpretation of the Gram stain for BV has been proposed (141) and evaluated at multiple institutions. This system puts greater weight on the presence or absence of the morpho- 
TABLE 2. Scoring system (0 to 10) for Gram-stained vaginal smears ${ }^{a}$

\begin{tabular}{cccc}
\hline Score $^{b}$ & $\begin{array}{c}\text { Lactobacillus } \\
\text { morphotypes }\end{array}$ & $\begin{array}{c}\text { Gardnerella and } \\
\text { Bacteroides, morphotypes }\end{array}$ & $\begin{array}{c}\text { Curved gram- } \\
\text { variable rods }\end{array}$ \\
\hline 0 & $4+$ & 0 & 0 \\
1 & $3+$ & $1+$ & $1+$ or $2+$ \\
2 & $2+$ & $2+$ & $3+$ or $4+$ \\
3 & $1+$ & $3+$ & \\
4 & 0 & $4+$ & \\
\hline
\end{tabular}

${ }^{a}$ Morphotypes are scored as the average number seen per oil immersion field. Note that less weieght is given to curved gram-variable rods. Total score $=$ lactobacilli + G. vaginalis and Bacteroides spp. + curved rods. Reproduced with permission from reference 141 .

${ }^{b} 0$, no morphotypes present; $1,<1$ morphotype present; 2,1 to 4 morphotypes present; 3,5 to 30 morphotypes present; 4,30 or more morphotypes present.

types that are most reliably recognized, i.e., lactobacilli, small gram-negative or gram-variable rods (gardnerella or bacteroides), and curved gram-variable rods. These organisms were quantitated by using previous criteria (189), and the smear was assigned a score (Table 2). A slide with a total score of 7 or more is interpreted as BV; 4 to 6 , as intermediate; and 0 to 3 , as normal. When the method was compared with that used by Krohn et al. (110), intracenter correlation rose from 0.61 to 0.82 . Bacteroides spp. and Gardnerella spp. were grouped together because participating centers had difficulty distinguishing between the two. It is unclear from the description of methods whether the Kopeloff modification of the Gram stain had been used. Use of this method is a key step in preventing overdecolorization of grampositive rods such as Gardnerella spp. This study was performed with a population of pregnant women whose signs and symptoms of BV were not specified. The benefits of this method for diagnosis of $\mathrm{BV}$ in symptomatic women has not yet been determined.

In general, authors agree that the Gram stain is more sensitive than fishy odor and gas-liquid chromatography and more specific than clue cells and culture for $G$. vaginalis (see below). It is less subjective than all of the clinical criteria other than $\mathrm{pH}$. For clinical settings in which a microscope is unavailable, a swab or slide can be sent to a laboratory for processing. Gram stain also has the advantages that specimens can be batched and results can be reviewed.

The current reference method for diagnosis of $\mathrm{BV}$ is use of the clinical criteria. Gram stain diagnosis correlates well with clinical diagnosis and is an accepted alternative method. Eschenbach et al. (49) suggest that Gram stain has a lower positive predictive value for diagnosis of $\mathrm{BV}$ in populations in which the prevalence of $\mathrm{BV}$ is low. Conversely, one could speculate that the Gram stain is a more sensitive indicator of alterations in the vaginal flora than the clinical criteria.

\section{MICROBIOLOGY OF BV}

\section{Facultative Organisms}

G. vaginalis. (i) Characteristics. In 1953, Leopold described a previously unrecognized Haemophilus-like organism associated with prostatitis and cervicitis (118). Two years later, Gardner and Dukes described $H$. vaginalis as the etiologic agent of BV (52). Because it required neither hemin ( $\mathrm{X}$ factor) nor NAD (V factor) and because it sometimes appeared to be gram positive and formed "Chinese letters," it was removed from the genus Haemophilus and renamed Corynebacterium vaginale (229). Because the organism is catalase negative and lacks arabinose in its cell wall, it does not conform to the genus description for Corynebacterium. Taxonomic studies performed by Greenwood and Pickett (61) and Piot et al. (153) showed a lack of genetic relationship between this organism and the organisms in other morphologically and physiologically similar genera, so $C$. vaginale was renamed $G$. vaginalis (61). It remains the sole species in this genus.

G. vaginalis (61) is a facultatively anaerobic, nonsporeforming, nonencapsulated, nonmotile, pleomorphic, gramvariable rod. Growth is best at $35^{\circ} \mathrm{C}$ and is enhanced by carbon dioxide. It is indole, nitrate, and urease negative. Rare anaerobic strains exist (122). Pili have been recognized on its surface $(19,99)$.

G. vaginalis commonly stains gram negative or gram variable. It is more likely to appear gram positive when stained with the Kopeloff modification of the Gram stain (80). As revealed by electron microscopy, its cell wall has been described as being gram positive $(164,168)$, gram negative (33), or typical of neither type (61). The cell wall contains alanine, glutamic acid, glycine, and lysine (70), and the cell membrane contains predominantly hexadecanoic $(16: 0)$, octadecenoic $(18: 1)$, and octadecanoic (18:0) acids without hydroxy fatty acids (36). The amino acid and fatty acid profiles are typical of gram-positive organisms. Endotoxic activity has been detected in cell extracts by using the Limulus amoebocyte assay (61), but lipid A was not present $(61,168)$. Like gram-positive organisms, $G$. vaginalis is susceptible to penicillin, clindamycin, and vancomycin but resistant to colistin and nalidixic acid (128). However, because of its taxonomic uncertainty, $G$. vaginalis is currently grouped with gram-negative bacteria in the 9th edition of Bergey's Manual (62).

Numerous identification schemes based on various batteries of tests have been recommended for $G$. vaginalis $(6,63$, $91,104,150,154,155,162,228)$. The following characteristics have been demonstrated: oxidase negative; catalase negative; thin, gram-variable rod shape; hippurate hydrolysis; fermentation of starch, raffinose, glucose, maltose, and sucrose but not melibiose or mannitol; production of $\alpha$-but not $\beta$-glucosidase; resistance to sulfonamides (104); and susceptibility to bacitracin, nitrofurantoin, sulfonamides (155), metronidazole, and bile; and beta-hemolysis on human but not sheep blood. Susceptibility to sodium polyanethol sulfonate on brucella agar with $5 \%$ sheep blood has been described (162). To obtain accurate results, the media must be prepared and methods must be followed exactly as published. The usefulness of the API 20 Strep strip (API System, La Balme les Grottes, Montalieu-Vercieu, France) (91), but not that of API 20A (Analytab Products, Inc., Plainview, N.Y.) or Minitek (Becton Dickinson, Cockeysville, Md.), has been described previously (6). For routine use in a diagnostic laboratory, the presence of thin, gramnegative or gram-variable, short rods that are catalase negative and produce a 1- to $2-\mathrm{mm}$ zone of beta-hemolysis with diffuse edges on human blood bilayer-Tween 80 agar after 48 $\mathrm{h}$ of incubation in carbon dioxide will correctly identify $G$. vaginalis $>97 \%$ of the time $(151,176)$.

(ii) Associations with BV. In 1955, using Bacto Proteose Peptone no. 3 agar with $10 \%$ sheep blood incubated in carbon dioxide, Gardner and Dukes recovered $G$. vaginalis from $127(92 \%)$ of 138 women with BV, $12(20 \%)$ of 61 with $T$. vaginalis vaginitis, and 0 of 121 controls (52). Some subsequent studies were unable to support this association; 
McCormack et al. (129) isolated $G$. vaginalis from $38 \%$ of women with BV and $30 \%$ of women without BV. Discrepancies may have been due to the difficulty in recovering this rather fastidious organism or, at that time, the lack of a standard method for clinical diagnosis of BV.

Because $G$. vaginalis produces small nondescript colonies on the routine microbiological media that support its growth, several selective differential media have been developed for their primary isolation. Dunkelberg et al. used peptonestarch-dextrose agar and recognized starch-utilizing colonies of $G$. vaginalis by using a dissecting microscope (41). Greenwood and Pickett (60), recognizing the ability of $G$. vaginalis to hemolyze human but not sheep blood, developed V (vaginalis) agar for its isolation. V agar contains Columbia agar base, $1 \%$ Proteose Peptone no. 3, and 5\% whole human blood. Ison et al. (95) used Proteose Peptone no. 3 with human blood plus nalidixic acid, amphotericin B, and gentamicin or colistin. The gentamicin-containing version better inhibited endogenous flora, but neither medium inhibited lactobacilli. Shaw et al. (176) used human blood agar, which had the same composition as V agar without the Proteose Peptone no. 3.

In 1982, Totten et al. (216) described selective differential human blood bilayer-Tween 80 agar for the recovery of $G$. vaginalis from vaginal fluid. This medium is composed of Columbia agar base with colistin, nalidixic acid, and amphotericin B. After a 14-ml basal layer is allowed to solidify, an overlay of $7 \mathrm{ml}$ of the same medium with $5 \%$ outdated human bank blood is made. Human blood bilayer-Tween 80 agar was compared with $\mathrm{V}$ agar for detection of $G$. vaginalis in vaginal fluid from 35 college students. Human blood bilayerTween 80 and $\mathrm{V}$ agars, respectively, detected $G$. vaginalis in 100 and $83 \%$ of women with BV and 69 and $28 \%$ of healthy women. Hemolysis was enhanced when the bilayer format was used and Proteose Peptone no. 3 was added, and it was further enhanced when Tween 80 was added.

Other studies have also shown that $G$. vaginalis is a common member of the endogenous vaginal flora (49). Using a semiquantitative technique, Totten et al. (216) showed that women with and without BV had 3 to $4+G$. vaginalis 91 and $26 \%$ of the time, respectively. Other quantitative studies have shown a similar disparity between patients and controls $(189,195,206)$. Of the 82 women with 3 to $4+G$. vaginalis, 40 had a clinical diagnosis of BV (positive predictive value, 49\%) (216). Clinical studies have also shown that the rate of vaginal colonization by $G$. vaginalis in women successfully treated for BV is similar to that in healthy controls $(17,47$, $152,195)$. On the basis of these data, culture for $G$. vaginalis is not recommended either for diagnosis of $\mathrm{BV}$ or for test of cure.

G. vaginalis can also be detected in vaginal secretions or identified in pure culture with fluorescent antibodies $(26,69$, $159,205,221$ ) and enzyme immunoassay (21).

While detection or quantitation of $G$. vaginalis in vaginal fluid cannot be used as a diagnostic test for BV, the increased prevalence and concentration of $G$. vaginalis in patients with this syndrome suggests that $G$. vaginalis plays a role in $\mathrm{BV}$ even though it is not the sole etiologic agent. Its presence at a high concentration in essentially all women with BV suggests that its presence in the vaginal flora may be a prerequisite to development of $\mathrm{BV}$.

Facultative lactobacilli. Facultative lactobacilli predominate in the healthy vagina. Lactobacilli are thought to be responsible for maintaining an acid $\mathrm{pH}$ in the vagina by metabolism of the glucose generated by metabolism of glycogen $(202,227)$. Low $\mathrm{pH}$ may directly inhibit some organisms. For every $1.0-\mathrm{U}$ decrease in $\mathrm{pH}$, the oxidationreduction potential increases $60 \mathrm{mV}(81)$. Therefore, low pH may also inhibit anaerobic organisms by maintaining a higher $E_{h}$ and a less reduced environment. Hydrogen peroxide produced by facultative lactobacilli may also control the quantity of catalase-negative organisms such as anaerobes (48) (see subsection, Microbial Antagonism).

In patients with BV, lactobacilli are replaced by $G$. vaginalis and a mixed, predominantly anaerobic flora. The decrease in lactobacilli in patients with BV and the return of these organisms after therapy have been documented by using cultural $(17,195)$ and microscopic $(1,189)$ techniques. The species of vaginal lactobacilli were determined in a recent study (48). Hydrogen peroxide-producing lactobacilli were recovered from $27(96 \%)$ of 28 healthy women and from $4(6 \%)$ of 67 women with BV. Hydrogen peroxide-producing Lactobacillus acidophilus, L. jensenii, and L. catenaforme were found alone or in combination with one another or with other Lactobacillus sp. in $16(76 \%)$ of 21 healthy women and $3(5 \%)$ of 66 women with BV whose lactobacilli were identified to the species level. These data are further discussed below (see subsection, Microbial Antagonism).

Mycoplasma hominis. $M$. hominis has been associated with BV in pregnant women $(110,126)$ and in nonpregnant women from student health clinics $(88,109,117,133,149)$ and sexually transmitted disease clinics $(109,145)$. It is present in 24 to $75 \%$ of women with BV and 13 to $22 \%$ of women without BV. Its role as an etiologic agent in BV is unclear. $M$. hominis persisted in $50 \%$ of women treated with sulfonamide, $27 \%$ of those treated with doxycycline, $88 \%$ of those treated with ampicillin, and 38 to $40 \%$ of those treated with metronidazole $(109,149)$, and by 35 days after therapy, it had recolonized $70 \%$ of the metronidazole-treated women and $83 \%$ of the ampicillin-treated women (109). The persistence of $M$. hominis after therapy for BV was associated with the persistence of Bacteroides spp. (109). M. hominis was associated with an abnormal gas-liquid chromatogram and the presence of diamines whether or not $G$. vaginalis was also present (145). Serum antibody levels to $M$. hominis were significantly higher in women with BV (145). Most recently, after adjustment for coinfection with Chlamydia trachomatis, $T$. vaginalis, or Candida albicans or for colonization by other BV-associated flora, $M$. hominis remained positively associated with BV and therefore is interpreted as being independently associated with BV $(110,126)$.

Viridans streptococci. Rabe et al. (157) identified viridans streptococci in the vaginas of pregnant women with BV or a normal vaginal exam. While $S$. acidominimus was the fourth most common species isolated from the healthy vagina, it and $S$. intermedius were the most common species recovered from women with BV $(P<0.001)$. $S$. morbillorum was also more common in women with BV. Viridans streptococci were associated with BV by univariate (157) but not by multivariate $(110,126)$ analysis.

\section{Anaerobic Bacteria}

General. Pheifer et al. (149) were the first to suggest that anaerobic bacteria might be involved in the pathogenesis of BV. They observed that, when patients with trichomoniasis and signs of BV were treated with metronidazole, an antimicrobial agent with activity against protozoa and anaerobic bacteria, the signs of BV were eradicated. Subsequent studies have shown that Bacteroides spp. and Peptostreptococcus spp. $(17,51,65,195,206)$. Mobiluncus spp. (17, 195), Eubacterium spp. (51, 196), Fusobacterium spp. (151), 
and Veillonella parvula (151) are associated with BV. The predominant anaerobic gram-negative rods are Prevotella bivia, Prevotella disiens, Porphyromonas spp., and Prevotella spp. The peptostreptococci that produce butyric acid may predominate over those that do not (195).

Mobiluncus spp. (i) Characteristics. Mobiluncus spp. are the most recently recognized member of the vaginosisassociated flora. The literature on this genus has been summarized recently (192). Mobiluncus spp. are curved, gram-variable, motile organisms. Bacterial cells with this morphology were detected in vaginal fluid before the turn of the century (112) and first recovered in the laboratory in 1913 (37). In 1980, large and small morphotypes were described (42), and the organisms were named "vibrions succinoproducteurs," or succinate-producing vibrios. Because they are anaerobic organisms, their characteristics are inconsistent with those of the genus Vibrio. Biochemical and genetic comparisons of Mobiluncus spp. with morphologically similar organisms showed Mobiluncus spp. to be unique, and so these organisms were independently placed into two new genera, Mobiluncus (199) and Falcivibrio (66). Because the name Mobiluncus was validated first, it has priority. Two species have been recognized, Mobiluncus curtisii (Falcivibrio vaginalis) and Mobulincus mulieris (Falcivibrio grandis), representing the small and large morphotypes, respectively. Two subspecies of $M$. curtisii have been described: $M$. curtisii subsp. curtisii and $M$. curtisii subsp. holmesii (199).

Mobiluncus spp. are slowly growing, fastidious organisms requiring an enriched medium for growth. They are indole, catalase, oxidase, and $\mathrm{H}_{2} \mathrm{~S}$ negative. No spores have been observed. Growth in broth is stimulated by rabbit $(197,199)$ or horse $(42,85,139,214)$ serum or fermentable carbohydrates such as maltose or glycogen (199). M. curtisii, the short form, may be only slightly bent and appear coryneform. It generally stains gram variable or gram positive. $M$. mulieris, the long form, is more crescentic or moonlike and may form exaggerated half-circles. It almost invariably stains gram negative. Despite these atypical Gram stain characteristics, electron microscopic studies have shown that Mobiluncus spp. have a gram-positive cell wall $(30,66$, $183,199)$. Other data supporting its gram positivity include absence of lipopolysaccharide (27); susceptibility to penicillin, clindamycin, and vancomycin and resistance to colistin and nalidixic acid $(66,79,140,180,190,200,201)$; and absence of hydroxy fatty acids from the cell wall $(27,30,181$, 182).

Mobiluncus spp. are flagellated and demonstrate a corkscrew motility on wet mount of vaginal fluid and in pure culture (37). Because the other BV-associated flora are nonmotile and because other motile organisms such as $E$. coli are not commonly found in high concentration in the vagina, detection of such motile cells has been used in the diagnosis of BV (215). M. mulieris has up to eight flagella with multiple origins, and $M$. curtisii has up to six flagella with a common origin. Attachment is either subpolar or at a more central location on the concave side $(66,200,201,208)$.

Members of both species produce succinic, acetic, and lactic acids as major metabolic by-products $(30,66,78,79$, $87,199,220)$. Malic acid is produced from fumarate $(66,199)$. $M$. mulieris can be distinguished from $M$. curtisii by production of strong acid from glycogen and synergistic hemolysis, while $M$. curtisii produces $\alpha$ - and $\beta$-galactosidases, is stimulated by arginine and produces ammonia from it, hydrolyzes hippurate, and is susceptible to $\mathrm{O} / 129(2,4$-diamino-6,7diisopropylpteridine phosphate). $M$. curtisii subsp. curtisii and $M$. curtisii subsp. holmesii can be distinguished by migration through soft agar by the former and reduction of nitrate to nitrite by the latter (199).

Several selective media for the primary isolation of one (214) or both $(85,184,194,198)$ species of Mobiluncus have been described, none of which is commercially available. All use a Columbia agar base with colistin, nalidixic acid, and tinidazole as inhibitory agents. Like metronidazole, tinidazole is a nitroimidazole with activity against anaerobic bacteria. Alkaline pretreatment $(146,147)$ and cold enrichment (184) have been shown to improve the rate of recovery.

Polyclonal (138) and monoclonal $(50,98,147)$ antibodies have been produced. Some have shown species $(50,98,138$, 147), subspecies (50), and partial genus ( $M$. mulieris and $M$. curtisii subsp. holmesii) (50) specificity.

Whole-cell DNA probes have also been developed (165). Culture was a more sensitive method than DNA probe for detection of Mobiluncus species in clinical specimens, but DNA probes had the advantage of identifying the species present (166).

(ii) Association with BV. The prevalence of Mobiluncus spp. in the vagina has been determined in numerous studies by one or more methods described above and has been reviewed recently (192). With microscopy, the prevalence of Mobiluncus spp. in BV has been reported to be as high as $77 \%$. With culture, the prevalence ranges from 14 to $96 \%$ in women with vaginosis and is $<6 \%$ in controls $(83,192)$. Holst (83) studied a group of 148 women with BV, 143 of whom had one $(n=32)$ or both $(n=111)$ species of Mobiluncus spp. in the vagina. Neither species was found in 69 healthy vaginas.

\section{BIOCHEMICAL CHARACTERISTICS OF BV}

\section{Fishy Odor}

Pheifer et al. (149) were the first to report the presence of a fishy odor when $10 \%$ potassium hydroxide was added to vaginal fluid as it was prepared for microscopic examination for yeast vaginitis. Chen et al. (29) detected the presence of diamines in the vaginal fluid of women with BV but not in women without a clinical diagnosis of BV. They used high-voltage electrophoresis and two-dimensional thin-layer chromatography in two (29) or three (28) phases. Putrescine and cadaverine, the decarboxylation products of arginine and lysine metabolism, respectively, predominated. These compounds are present as the nonvolatile salt form in the vagina, but become volatile at alkaline $\mathrm{pH}$ and emit a fishy odor. This phenomenon occurs not only when alkali is added in the laboratory but also in vivo during intercourse, when semen, which has an approximate $\mathrm{pH}$ of 7 , is introduced into the vagina. Semen increases the $\mathrm{pH}$ of the vaginal secretions so that the patient and her partner may notice a fishy odor, the most common symptom of women seeking medical care for BV (2).

In a study of 520 college students and 30 women referred to a vaginitis clinic because of signs and symptoms of $\mathrm{BV}$, $173(88 \%)$ of 197 women with BV and $32(10 \%)$ of 323 without BV or trichomoniasis had diamines detected by thin-layer chromatography. After successful therapy with metronidazole, the diamines were no longer detectable (28). These data have been confirmed by others (169).

The microbial source of the diamines has been investigated. When pure cultures of $G$. vaginalis were grown in the presence of the appropriate amino acid substrate, diamine production could not be demonstrated (29). Diamine produc- 
tion by the mixed BV-associated flora was examined. Vaginal discharge from each of four women with BV was incubated on a prereduced blood agar plate for 4 days. The mixed flora was harvested and tested for diamine production with and without added metronidazole. Diamines were produced by the former but not the latter, suggesting that an anaerobic component of the BV-associated flora was responsible for diamine production. However, many strains of a wide variety of anaerobic bacteria, including Mobiluncus spp. (199), have been tested for diamine production. Although some strains identified as $V$. parvula produced putrescine and cadaverine, no consistent pattern of production has been found (188). Because Veillonella spp. have been described as requiring putrescine and cadaverine (105), these vaginal isolates may represent a new organism. Several explanations for the observations of Chen et al. (29) are possible: (i) an as yet unidentified, BV-associated anaerobic organism is responsible for amine production; (ii) the methods being used to stimulate amine production in pure cultures are inadequate; or (iii) a facultative organism whose growth is stimulated by anaerobic organisms is the producer. Further investigation of this issue is needed.

Trimethylamine is the predominant source of the characteristic odor of spoiling fish. Brand and Galask (20) performed gas chromatographic analysis of headspace samples of vaginal fluid from 11 women with $\mathrm{BV}$ and 10 women without BV. All of the former and none of the latter had detectable trimethylamine. Mobiluncus spp. (four strains) but not $G$. vaginalis (five strains) or Bacteroides spp. (two strains) from BV patients reduced trimethylamine oxide to trimethylamine in vitro (34).

Although its sensitivity and specificity are high, thin-layer chromatography used for diagnosis of $\mathrm{BV}$ by detection of amines is impractical in the clinical microbiology laboratory, and so the method remains a research tool. The presence of trimethylamine has not been sufficiently evaluated to determine the sensitivity and specificity of this indicator, but routine tests for this substance would also be impractical for use in diagnosis.

\section{Gas-Liquid Chromatography}

Anaerobic bacteria can usually be identified to the genus level by Gram stain morphology and identification of metabolic products of glucose metabolism as determined by gas-liquid chromatography $(80)$. Lactobacilli produce predominantly lactic acid; Porphyromonas spp., Prevotella spp., Bacteroides spp., and Mobiluncus spp. produce succinic acid; Peptostreptococcus spp. produce acetic acid with or without butyric acid; and $G$. vaginalis produces acetic acid. Some Porphyromonas spp., Prevotella spp., and Bacteroides spp. also produce propionic, butyric, isovaleric, and other acids.

In addition to being detectable by culture and Gram stain, the change from a lactobacillus-dominated vaginal flora to one in which lactobacilli are replaced by a mixed, predominantly anaerobic flora has been detected by gas-liquid chromatographic analysis of vaginal fluid $(2,96,103,151,195$, $211,213)$. Vaginal fluid may be collected either by vaginal wash $(2,96,103,195)$ or on swabs placed in saline or distilled water $(151,211,213)$. Gas-liquid chromatography using a gas-liquid chromatograph equipped with a flame ionization detector was first compared with culture and a clinical diagnosis of $\mathrm{BV}$ in 1980 (195). Readers are referred to that article for a complete description of the method. Vaginal fluid from women with BV was characterized by an in- creased quantity of succinic acid and a decreased quantity of lactic acid, indicating replacement of lactobacilli by Prevotella spp. and Mobiluncus spp. In the original description of gas-liquid chromatographic examination of vaginal fluid, there was a high degree of correlation with a clinical diagnosis of BV. Some subsequent studies have found a lesser correlation due, at least in part, to changes in the methods used. The sensitivity of gas-liquid chromatography for detecting an abnormal succinate/lactate ratio or the presence of volatile acids other than acetate is decreased when a chromatograph equipped with a thermal conductivity detector is used $(211,213)$ and will also be affected by the method for clinical diagnosis of BV (96). The gas-liquid chromatographic pattern returns to normal within 3 to 7 days after appropriate antimicrobial therapy is begun $(103,195)$.

While gas-liquid chromatography is another tool available for diagnosis of $\mathrm{BV}$, it would not be practical in most settings because clinics and many hospital laboratories are not equipped with a gas-liquid chromatograph, and many of those that are lack one with a flame ionization detector (211). It has, however, proven to be a useful tool for studying the microbiology of BV.

\section{Proline Aminopeptidase}

Thomason et al. have described an assay for proline aminopeptidase to diagnose BV $(212,213)$. In this assay, enzyme in vaginal fluid cleaves the substrate L-proline $\beta$-naphthylamide and releases naphthylamine. Fast garnet salt forms a red or pink complex with the product and remains yellow or orange in its absence. The accuracy of this 5-min test was compared with clinical diagnosis in 116 women with BV and 151 healthy controls; it had a sensitivity of $81 \%$, a specificity of $96 \%$, a positive predictive value of $87 \%$, and a negative predictive value of $87 \%$. Proline aminopeptidase was more sensitive than gas-liquid chromatography performed with a thermal conductivity detector. Women with trichomoniasis alone or with BV as a mixed infection with either trichomoniasis or yeast vaginitis were not studied. The BV-associated organisms that produce proline aminopeptidase have not been identified.

While recognition of diamines, trimethylamine, volatile and nonvolatile fatty acids, and proline aminopeptidase have added to our understanding of the microbiology of $\mathrm{BV}$, none are currently useful in the routine diagnosis of BV.

\section{SEQUELAE}

\section{Pelvic Inflammatory Disease}

In 1973, Eschenbach et al. (46) first reported the association of anaerobic bacteria with pelvic inflammatory disease. Since that time, several authors have associated BV with pelvic inflammatory disease. Goldacre et al. (54), in a study of women attending a family planning center, reported that troublesome vaginal discharge, backache, and postcoital spotting occurred more frequently in women who were colonized by anaerobic gram-negative rods. The association was greater in women who also wore an intrauterine contraceptive device. Pelvic inflammatory disease associated with Mycoplasma hominis was found in women who had vaginal fluid gas-liquid chromatographic findings indicating BV (133). In another study of 642 women (49), adnexal tenderness was found significantly more often in women with (4\%) than in those without $(0.3 \%)$ Gram stain criteria for BV by multivariate analysis $(P=0.04)$. In a study of 45 women with 
pelvic inflammatory disease, 9 of 35 with and 0 of 10 without salpingitis and endometritis or endometritis alone had BV (145) diagnosed by abnormal vaginal fluid gas-liquid chromatography. Others have reported similar findings $(82,106$, 117). In another study (71), postabortal pelvic inflammatory disease occurred in $9(25 \%)$ of 36 women who had vaginitis during the previous year compared with $4(5 \%)$ of 74 without prior vaginitis $(P<0.005)$. Association with specific organisms from cervical cultures collected at the time of pelvic inflammatory disease could not be made. Larsson and Bergman (115) and Larsson et al. (116) found an association of Mobiluncus spp. with irregular bleeding episodes or discharge suggestive of upper genital tract infection. All patients responded to therapy with oral metronidazole. Hillier et al. (76) did not find an association of Mobiluncus spp. with irregular bleeding episodes or changes in menstrual bleeding.

\section{Adverse Outcome of Pregnancy}

In the pregnant woman, $\mathrm{BV}$ has been associated with preterm birth, premature rupture of membranes, and chorioamnionitis. These sequelae have been reviewed recently (125). Gravett et al. (58) studied the outcome of pregnancy in 534 women in the second and third trimesters of pregnancy. BV was diagnosed by gas-liquid chromatographic examination of vaginal fluid collected on swabs. After correcting for demographic and obstetric variables associated with adverse pregnancy outcome and for the presence of Chlamydia trachomatis, there were associations between BV and preterm premature rupture of membranes (odds ratio [OR], 2.0; $P<0.05$ ), preterm labor at $<37$ weeks (OR, 2.0: $P<0.05$ ), and amniotic fluid infection (OR, 2.7; $P<0.05)$.

Amniotic fluid infection was studied in 54 women who presented in preterm labor at $<35$ weeks of gestation with singleton gestations, intact fetal membranes, and $\leq 4 \mathrm{~cm}$ of dilation (57). Vaginal and cervical specimens were collected from patients and matched controls. Amniocentesis was performed only on study patients. Tocolytic agents were used as appropriate to inhibit labor. BV, diagnosed by an abnormal vaginal fluid gas-liquid chromatographic pattern, was more common in patients $(43 \%)$ than in controls $(14 \% ; P$ $=0.02)$. The organisms recovered from the amniotic fluid represented vaginal flora, i.e., G. vaginalis, Fusobacterium nucleatum, Prevotella melaninogenica, Ureaplasma urealyticum, Candida albicans, and E. coli. The mean gestational age at onset of preterm labor did not differ in women with sterile or culture-positive amniotic fluid. However, the mean gestational age at delivery was significantly shorter (29.2 \pm 3.1 weeks) for women with culture-positive amniotic fluid than for those with culture-negative amniotic fluid (36.2 \pm 4.0 weeks; $P<0.05$ ). This difference appeared to be due to the fact that tocolysis was achieved in 0 of 4 women with eubacteria or yeasts in their abdominal fluid cultures but in $26(81 \%)$ of 32 with no organisms or mycoplasmas $(83 \%)$ in their fluid. Similar microbiological data have been reported by others (178).

The frequency of genital infection has been compared among women in premature labor who delivered preterm ( $<37$ weeks), women in preterm labor who delivered at term, and control women who delivered at term (126). Women were evaluated for intra- and postpartum fevers, amniotic fluid infection, cervicitis, vaginitis, and BV. Vaginal wash cultures were performed for aerobic and anaerobic bacteria. BV was diagnosed by Gram stain criteria. Patients who delivered before 37 weeks of gestation had a significantly higher frequency of premature rupture of membranes, intra- partum fever, and postpartum fever than those who delivered after 37 weeks of gestation. Patients who delivered before 37 weeks of gestation were more likely to have BV (OR, 2.3; $P=0.03$ ) and to be colonized by black-pigmented Porphyromonas spp. or Prevotella spp. $(P<0.05)$, Chlamydia trachomatis $(P<0.05)$, or $U$. urealyticum $(P<0.01)$. They were less likely to be colonized by lactobacilli (OR, $0.2 ; P=0.002)$. In another study, high vaginal fluid concentrations of Prevotella bivia and Bacteroides fragilis were associated with an increased rate of preterm delivery, and a high vaginal fluid concentration of Lactobacillus spp. was associated with a low risk (111).

Hillier et al. (77) studied the role of microorganisms in prematurity by culturing the space between the chorion and amnion (chorioamnion), histologically examining the placenta for inflammatory cells (chorioamnionitis), and gathering obstetric and demographic information. Women were placed in one of three groups: premature labor and delivery (preterm patients), premature labor ( $<37$ weeks) but delivery at term (full-term patients), and labor and delivery at term ( $>37$ weeks, controls). Isolation of $U$. urealyticum was associated with premature delivery but not premature labor alone. Organisms associated with BV including Mycoplasma hominis were more common in preterm $(45 \%)$ and full-term (28\%) patients than in controls (7\%). Mycoplasma hominis was not associated with preterm labor or delivery. BV in the mother was also associated with choramnionitis and preterm delivery. Histological chorioamnionitis was associated with placental organisms in both preterm and full-term patients. The presence of organisms in the chorioamnion was associated with chorioamnionitis regardless of gestational age at delivery even after correction for the effect of ruptured membranes. The highest rate of histological chorioamnionitis was found among women who delivered most prematurely. The authors concluded that their data strongly suggest that chorioamnionitis and infection of the chorioamnion may be causes of premature birth.

It is important to know whether the outcome of pregnancy in women with $\mathrm{BV}$ who are in the second and third trimester can be improved with antimicrobial therapy. In a recent study, women were treated with oral erythromycin base (131). There were no overall differences between patients and controls in occurrence of preterm labor, preterm birth, or low-birth-weight infants. Premature rupture of membranes before labor occurred less frequently in patients $(6 \%)$ than in controls $(16 \% ; P=0.01)$. Erythromycin reduced the risk of premature rupture of membranes in women who were colonized by erythromycin-susceptible organisms, e.g., Chlamydia trachomatis, U. urealyticum, and Staphylococcus aureus. In this study, preterm birth was not associated with BV by Gram stain or proline aminopeptidase tests. Amoxicillin treatment of BV during pregnancy did not reduce the rate of pregnancy complications (39). Treatment with intravenous mezlocillin for $48 \mathrm{~h}$ followed by treatment with oral ampicillin until delivery has been shown to reduce chorioamnionitis and delay delivery (102). Further studies with antimicrobial agents that are effective at vaginal fluid $\mathrm{pH}$ and against anaerobic bacteria are needed.

\section{Postpartum Endometritis}

$\mathrm{BV}$ has also been associated with postpartum endometritis. Watts et al. (223) studied 150 women with positive endometrial cultures. Sixty-one percent had BV-associated flora (G. vaginalis, Prevotella bivia, Bacteroides spp., and Peptostreptococcus spp.). Some also had M. hominis or $U$. 
urealyticum or both. G. vaginalis was recovered from endometrial cultures of 57 patients and represented $19 \%$ of the blood culture isolates. Anaerobes (all BV associated except three $B$. fragilis and four Clostridium perfringens isolates) represented $25 \%$ of endometrial and $29 \%$ of blood isolates. Thirty-five endometrial and four blood cultures were positive for Mycoplasma hominis, usually accompanied by other BV-associated flora.

$\mathrm{BV}$ is also a risk factor for post-Cesarean endometritis (224). BV was diagnosed by Gram stain of vaginal fluid that was collected at the time of admission for delivery. BV was associated with development of postpartum endometritis by multivariate analysis (OR, 5.8; 95\% confidence interval [CI], 3.0 to 10.9), after adjusting for maternal age, duration of labor, and duration of membrane rupture. Bacteroides spp., Peptostreptococcus spp., and G. vaginalis, but not Mycoplasma hominis, were isolated more frequently from the endometrium of women with BV than from women with a normal vaginal Gram stain.

\section{Cuff Cellulitis}

BV as well as trichomoniasis have been recognized recently as risk factors for cuff cellulitis after abdominal hysterectomy (187). BV was diagnosed by standard criteria, and trichomoniasis was diagnosed by microscopic examination of a saline wet mount. Patients with BV alone or BV and trichomoniasis were at greater risk of developing cuff cellulitis, abscess, or both (relative risk, $3.2 ; \mathrm{CI}, 1.5$ to $6.7 ; P=$ 0.005 ) than controls. Patients with trichomoniasis alone were also at increased risk (relative risk, $3.4 ; \mathrm{CI}, 1.6$ to $7.1 ; P=$ 0.002).

\section{Urinary Tract Infections}

In another study, women who presented with symptoms of urinary tract infection were evaluated for clinical diagnosis of BV, urinary tract infection, and introital, urethral, and vaginal colonization by $E$. coli $(89)$. BV, an abnormal vaginal fluid gas-liquid chromatographic pattern, increased vaginal fluid $\mathrm{pH}$, and decreased colonization by lactobacilli were seen in women who had $E$. coli urinary tract infection and used a diaphragm. The authors concluded that, while these changes are associated with diaphragm use, they do not indicate causality.

\section{Other}

Other infections that have been associated with a mixed BV flora include neonatal scalp abscesses (130), nonpuerperal breast abscesses $(14,45,53,203,204,225)$, and umbilical and mastectomy wounds (53). G. vaginalis as a single agent has also been associated with urinary tract infections and bacteremia (191).

Serologic studies have recently implicated Mycoplasma hominis in the etiology of tubal factor infertility and ectopic pregnancy (134): 23 (48\%) of 48 women with damaged tubes due to secondary infertility and $2(10 \%)$ of 21 with damaged tubes due to primary infertility had serologic evidence of Mycoplasma hominis infection $(P<0.05)$.

Women with BV are at increased risk of pelvic inflammatory disease including postabortal pelvic inflammatory disease, preterm birth, premature rupture of membranes, chorioamnionitis, and associated fetal loss, as well as postpartum and post-Cesarean endometritis and cuff cellulitis.

\section{PATHOGENESIS}

\section{Natural History}

Few studies have looked at the natural history of untreated BV. Gardner and Dukes monitored an unnamed number of their 11 patients for 4 months. These patients had acquired experimental BV by vaginal fluid transfer: none showed spontaneous cure or improvement (52). Bump et al. (25) studied women with asymptomatic BV diagnosed by the presence of abnormal discharge (defined as excessive or of abnormal consistency) or fishy odor. After the initial visit, patients were seen monthly for 5 months. Subjects were not treated with antibiotics unless they became symptomatic. After 6 months, abnormal discharge persisted in $22 \%$ of the women and amine odor persisted in $27 \%$. In another study in which a clinical diagnosis was made by Gram stain criteria, 24 asymptomatic women with BV were monitored for 4 months. Seventeen had persistent BV, and seven became healthy without treatment (22). Several other studies have shown that spontaneous remission of the signs of BV occurs in 25 to $43 \%$ of adults $(76,120,152)$ and adolescents (24). This observation deserves further study.

\section{Sexual Transmission}

In 1955, Gardner and Dukes (52) inoculated 13 vaginosisfree women with a pure culture of $G$. vaginalis. Two became colonized but had no evidence of vaginosis, and one became symptomatic. There was no control group. In a subsequent study, 29 pregnant volunteers with no signs of BV were inoculated intravaginally with $2 \mathrm{ml}$ of a suspension, $10^{10}$ $\mathrm{CFU} / \mathrm{ml}$, of one of four G. vaginalis isolates. Five (56\%) of 9 so challenged with organisms in the log phase of growth and $2(10 \%)$ of 20 challenged with organisms in the stationary phase of growth became colonized with $G$. vaginalis, as evidenced by cultural and microscopic methods. The development of signs and symptoms was not discussed, suggesting that colonization could be achieved in this manner. In an additional experiment (52), 11 of 15 vaginosis-free women who were inoculated intravaginally with material from the vaginas of women with $\mathrm{BV}$ developed $\mathrm{BV}$, and the syndrome was passed a second time into two patients. Because they thought that $G$. vaginalis was present in pure culture in cases of BV, Gardner and Dukes interpreted these data as indicating that $G$. vaginalis is the etiologic agent of BV. While newer data indicate that this is not the case, the data of Gardner and Dukes do suggest that BV may be sexually transmitted. While women commonly complain of an onset of BV symptoms coincident with beginning a sexual relationship with a new partner, therapeutic trials have not shown a decrease in recurrence rate among women whose partners were treated compared with control couples in which the male partner was untreated $(132,137,219)$.

Evidence of sexual transmission of BV has come from other studies. In a recent study examining the use of the spermicidal agent nonoxynol 9 as a prophylaxis for sexually transmitted diseases (8), the number of sexual partners that a woman had during the month preceding a follow-up visit was directly related to the occurrence of $\mathrm{BV}$. Women who had $\geq 3$ partners had a relative rate of 1.77 compared with women with 0 to 1 partner $(95 \% \mathrm{CI}, 1.17$ to 2.69$)$. There was no association between the rate of $\mathrm{BV}$ and the number of sexual episodes. In another study (5), asymptomatic BV was associated with sexual activity; women with two or more sexual partners within the prior 3 months had a relative risk 
of 2.5 (95\% CI, 1.4 to 4.5$)$. Symptomatic BV was associated with the use of an intrauterine device (relative risk, 7.7; 95\% CI, 2.1 to 28.4), but the risk did not increase with an increased number of sexual partners.

On the other hand, in a study of BV in postmenarcheal girls, $6(12 \%)$ of 52 virginal girls and $10(15 \%)$ of 68 sexually active girls had a clinical diagnosis of BV (24). These data argue against sexual transmission. Note that none of the study participants was symptomatic.

Over $90 \%$ of male partners of women with $\mathrm{BV}$ have urethral colonization by $G$. vaginalis (52), suggesting that sexual transmission of this organism may occur. Piot et al. (154) developed a biotyping scheme for G. vaginalis on the basis of reactions for lipase, hippurate hydrolysis, and $\beta$-galactosidase. Biotypes 1 (positive for all three characters), 2 (negative only for $\beta$-galactosidase), and 5 (positive only for hippurate hydrolysis) made up $\geq 80 \%$ of the strains isolated from women in Antwerp, Belgium; Seattle, Wash., and Nairobi, Kenya. Vaginal isolates of $G$. vaginalis and urethral isolates from the male partners of these infected women belonged to the same biotype when they were obtained within $24 \mathrm{~h}$ of each other. However, there was no difference in prevalence of biotypes between women with and without BV. Similar results have been found by Ison et al. in London, United Kingdom (97), Benito et al. in Madrid, Spain (13), and Scott et al. in Dublin, Ireland (173).

In a more recent study (22), oleate replaced egg yolk emulsion as the substrate for lipase activity, and the system of Piot et al. (154) was used in biotype $G$. vaginalis isolated from women with and without BV. Biotypes 1,5 , and 6 were the most common. Lipase-positive biotypes, biotypes 1,2 , 3 , and 4 , were more prevalent among women with $(41 \%)$ than among those without $(23 \%) \mathrm{BV}(\mathrm{OR}, 2.3 ; \boldsymbol{P}=0.003)$. Seventy women with normal vaginal exams were sampled on entry into the study and again 4 months later. Women who had BV at their second visit were more likely to have a new biotype $(90 \%)$ than those who continued to have a normal exam (57\%; OR, 6.7; $P=0.003)$. Women with a new sex partner were not significantly more likely to have acquired a new biotype of $G$. vaginalis than women who did not report a new sex partner $(P=0.15)$. Women with $\mathrm{BV}$ who were treated were more likely to have a change in $G$. vaginalis biotype $(86 \%)$ than those who were untreated $(63 \%$; OR, 3.9; $P=0.04)$. Among those who were treated, those who responded to therapy were no more likely to have acquired a new biotype (86\%) than those who had persistent BV $(87 \%$; $\mathrm{OR}, 2.2 ; P=0.15)$. These data indicate that lipase-positive strains of $G$. vaginalis are associated with $\mathrm{BV}$ and that treatment, but not a change in sexual partner, is associated with a change in $G$. vaginalis biotype.

A serotyping panel has been developed for $G$. vaginalis (97). Serotype C predominated among women with BV, but no control group was studied.

Few studies have sought an extravaginal reservoir of Mobiluncus spp. Holst (83) recently examined 148 women with BV, 82 male partners of 82 women with BV, 69 women without BV, 49 male partners of 49 women without BV, 4 homosexual men (two monogamous couples), 12 virginal girls, and 10 virginal boys for rectal, oral, and pharyngeal colonization by Mobiluncus mulieris, Mobiluncus curtisii, Mycoplasma hominis, and G. vaginalis. All adult women were also examined for vaginal colonization (see subsection, Mobiluncus spp.), and adult males were examined for colonization of the urethra and coronal sulcus. All patient groups had rectal colonization with one or more of these four organisms, except that G. vaginalis was not found in homo- sexual men. Rectal colonization with one $(n=81)$ or both $(n$ $=47)$ Mobiluncus species occurred in 128 women with BV. Similar data have been published previously $(64,86)$. Women with BV were more frequently colonized by all of these organisms. Colonization rates for all other groups were similar to one another. Colonization by these organisms of male partners of women with BV was greater than that of partners of healthy women and homosexual males, but the numbers were too low to reach statistical significance. Forty-four male partners of women with BV were again cultured after 2 weeks, during which condoms were used during intercourse. While rectal colonization persisted, colonization of the urethra and coronal sulcus did not, and colonization rates at the 2 -week follow up were similar between the two groups of patients. Mobiluncus mulieris, Mobiluncus curtisii, and G. vaginalis were not recovered from any oropharyngeal cultures, but Mycoplasma hominis was recovered from 12 . Holst interpreted these data to suggest that the female rectum is the source of these organisms and that sexual transmission of BV is unlikely.

Mobiluncus spp. have also been recovered from the seminal fluid of an infertile male (220).

\section{Microbial Antagonism}

Emphasis has been placed on inhibitors that may be produced by lactobacilli as a method of preventing colonization or overgrowth by less desirable vaginal flora. This role for lactobacilli has been better studied in enteric isolates. A fecal strain of Lactobacillus sp. has been shown to inhibit a wide variety of microorganisms, including Clostridium, Bacteroides, Bifidobacterium, Pseudomonas, Staphylococcus, and Streptococcus spp. and members of the family Enterobacteriaceae (177). Mårdh and Soltész (124) tested vaginal lactobacilli for such antibiosis and found that, while facultative bacteria and yeasts were inhibited, anaerobic bacteria were not.

Eschenbach et al. (48) have recently examined the role of hydrogen peroxide-producing vaginal lactobacilli in the control of other vaginal flora. Lactobacilli use flavoproteins for terminal oxidation and produce hydrogen peroxide. Most anaerobic bacteria lack catalase peroxidase and therefore cannot eliminate toxic hydrogen peroxide from the environment. The authors hypothesized that hydrogen peroxideproducing lactobacilli would be absent form women with BV but not from those without BV.

Tetramethylbenzidine medium was developed and used for the detection of hydrogen peroxide-producing organisms from the vaginas of women with $(n=67)$ and without $(n=$ 28) BV. Control women were significantly more likely than women with $\mathrm{BV}$ to be colonized by hydrogen peroxideproducing facultative lactobacilli (96 versus $6 \% ; P=0.001$ ). Anaerobic lactobacilli, none of which produced hydrogen peroxide, were found in $67 \%$ of women with BV and in $4 \%$ of controls and were found in the absence of facultative lactobacilli only in patients with BV $(P<0.0001)$. Few women had both facultative and anaerobic lactobacilli, and there was no difference between patients and controls. The authors suggested that the presence of hydrogen peroxideproducing lactobacilli in the vagina may be a nonspecific mechanism by which the growth of anaerobic organisms associated with BV is contained. In a subsequent study, the authors monitored a cohort of pregnant women without BV and found that the absence of hydrogen peroxide-producing lactobacilli was a risk factor for subsequent colonization by BV-associated anaerobes and the development of BV (75). 
Lactobacilli appear to play an important role in controlling the composition of the vaginal flora (160). In vitro inhibition of $G$. vaginalis and Prevotella bivia by hydrogen peroxideproducing lactobacilli has been shown recently (107). Antibacterial activity was inhibited by catalase and enhanced by myeloperoxidase plus halide. Adequate levels of peroxidase were found in vaginal fluid from $7(64 \%)$ of 11 women with a normal vaginal exam and in $8(80 \%)$ of 10 women with abnormal exams (6 with BV, 3 with cervicitis, and 1 with vestibular gland inflammation). These data strongly suggest that a major protective component missing from the vagina of women with BV is hydrogen peroxide produced by lactobacilli.

\section{Vaginal Redox Potential}

Holmes et al. (81) studied the oxidation-reduction potential $\left(E_{h}\right)$ of the vaginal epithelial surface of women with and without $\mathrm{BV}$ to investigate the association of anaerobic bacteria with this syndrome. In BV patients before therapy, the mean $E_{h}$ was $-92 \mathrm{mV}$ (range, 71 to $-257 \mathrm{mV}$ ) and the mean $\mathrm{pH}$ was 5.1 (range, 4.7 to 5.5). After therapy, the mean $\mathrm{E}_{\mathrm{h}}$ was $208 \mathrm{mV}$ and the $\mathrm{pH}$ was 4.2 . These values are comparable to those in women with a normal exam, i.e., 170 $\mathrm{mV}$ and $\mathrm{pH} 4.1$, respectively. The low $\mathrm{E}_{\mathrm{h}}$ in women with $\mathrm{BV}$ could not be solely attributed to the elevated $\mathrm{pH}$. It is not clear whether the decrease in $\mathrm{E}_{\mathrm{h}}$ or the increase in anaerobic bacteria occurs first in BV.

\section{Bacterial Products}

Amines associated with BV and malic acid produced by Mobiluncus spp. can cause irritation of mucous membranes. Volatile fatty acids (18), G. vaginalis (203), and succinate from vaginal fluid anaerobes (203) inhibit granulocyte chemotaxis. A proteinaceous toxin from $G$. vaginalis with activity against human erythrocytes, endothelial cells, and neutrophils has been described recently (167).

Labor is initiated by the action of prostaglandins $E_{2}$ and $F_{2 \alpha}\left(P_{2} E_{2}\right.$ and $P_{2} F_{2 \alpha}$ ), which are synthesized from longchain fatty acids. Free arachidonic acid, the precursor of $\mathrm{PGE}_{2}$ and $\mathrm{PGF}_{2 \alpha}$ syntheses, is made available from amnionic phospholipids by the action of phospholipase $A_{2}$. Bejar et al. (12) have shown that many of the bacteria associated with premature rupture of membranes and with BV (Fusobacterium spp., G. vaginalis, Peptostreptococcus spp., group B streptococcus, and Mycoplasma hominis) have phospholipase $A_{2}$ activity.

The concentration of endotoxin is higher in the vaginal fluid of women with BV than in that of women with a normal vaginal exam (179). In addition, various species of vaginal anaerobes produce enzymes, including collagenase and proteases.

The role of these products in causing BV or upper genital tract sequelae is unknown.

\section{Adherence}

Because attachment is the first step in infection and because clue cells are such a prominent feature of $\mathrm{BV}$, the adherence characteristics of $G$. vaginalis and Mobiluncus spp. have been studied. While clue cells are described as epithelial cells with coccobacillary organisms, epithelial cells studded with curved rods resembling Mobiluncus spp. have also been observed $(31,38,136,218)$. G. vaginalis adheres better to vaginal evithelial cells at between pH 5 and 6 (148).
Adherence of $G$. vaginalis to McCoy cells but not to erythrocytes correlated with the presence of clue cells in women who were the source of the strains studied (173). Adherence of Mobiluncus mulieris and M. curtisii was better at $\mathrm{pH} 7.5$ and 5.5 than at pH 4.0, and adherence of Prevotella bivia and $\boldsymbol{P}$. disiens was better at $\mathrm{pH} 7.5$ than at $\mathrm{pH} 5.5$ or 4.0 (136). Cook et al. (31) raised specific antisera against $\boldsymbol{G}$. vaginalis, Prevotella melaninogenica, Mobiluncus mulieris, Mobiluncus curtisii, and Fusobacterium nucleatum and used the antisera to examine in situ adherence to vaginal epithelial cells. Adherence by all species was demonstrated, but higher numbers of $G$. vaginalis adhered more frequently than the other organisms. When cell viability was determined by trypan blue exclusion, preferential adherence of vaginal bacteria to vital vaginal epithelial cells was seen (218). A glycocalyx may play a role in the attachment of Mobiluncus spp. to vaginal epithelial cells (38).

Association of specific blood group antigens with adherence of BV-associated flora has not been examined.

\section{Other}

Dextran production by Streptococcus sanguis I, S. sanguis II, and $S$. mutans may enhance ascension of these organisms to the upper genital tract (157).

\section{TREATMENT}

A considerable number of papers that compare therapies for BV have been published. I shall highlight those that add to our understanding of BV.

\section{Metronidazole versus Ampicillin}

Oral metronidazole has replaced ampicillin as the drug of choice for treatment of $\mathrm{BV}$. The recommended regimen is $500 \mathrm{mg}$ twice a day for 7 days (47). While ampicillin is active against $G$. vaginalis (128), cure rates in studies with appropriately long follow-ups have been as low as $43 \%$ (1). The reasons for ampicillin failure appear to be twofold. First, many of the Prevotella spp. present in the vagina during BV produce $\beta$-lactamase and are ampicillin resistant $(72,113)$. All of 10 patients with BV had $\beta$-lactamase-producing strains of one or more species of Prevotella spp. or Porphyromonas spp. (188). Second, ampicillin is active against lactobacilli (11). In contrast, metronidazole resistance among anaerobic gram-negative rods is rare, but metronidazole is inactive against facultative lactobacilli. Thus, metronidazole inhibits anaerobic organisms commonly associated with BV and yet allows recolonization by lactobacilli. These effects have been measured indirectly by examining Gram stains and performing gas-liquid chromatography on vaginal fluid collected after therapy with each of these agents (1). After metronidazole or ampicillin therapy, lactobacilli were detected microscopically in 9 of 9 and 3 of 10 samples, respectively $(P<0.001)$. The lactic acid peak height increased by $29 \pm 51 \mathrm{~mm}$ after ampicillin therapy and by $113 \pm$ $74 \mathrm{~mm}$ after metronidazole therapy $(P<0.001)$. Combining ampicillin or amoxicillin with a $\beta$-lactamase inhibitor might give some improvement in efficacy because of increased activity of this combination of antimicrobial agents against Prevotella spp. However, because the $\beta$-lactam agent would inhibit recolonization by lactobacilli, the efficacy would not be as great as that seen with metronidazole. Such data have been published (217). While metronidazole is active against gram-negative anaerobes and Mobiluncus mulieris, it is less 
active against G. vaginalis, Peptostreptococcus spp., and Mobiluncus curtisii $(190,201)$. Inhibition of $G$. vaginalis may be due in part to its increased susceptibility to the hydroxy metabolite of metronidazole (158), and yet about $50 \%$ of women who have a clinical cure after treatment with metronidazole continue to be colonized by $G$. vaginalis (1). Mobiluncus curtisii is not susceptible to hydroxymetronidazole $(190,201)$. It is possible that growth of metronidazoleresistant members of the BV-associated flora is stimulated by metronidazole-susceptible members, so that, when the former are inhibited, the latter also decline.

Oral metronidazole therapy has been compared with intravaginal metronidazole therapy $(15,44)$. In one study women were treated with either $500 \mathrm{mg}$ of intravaginal metronidazole once a day for 7 days or $400 \mathrm{mg}$ of oral metronidazole twice a day for 7 days (15). At the 4-week follow-up examination, the cure rates were $79 \%$ in the women treated with the intravaginal regimen and $74 \%$ in those treated with the oral regimen.

Oral amoxicillin has been shown to be no more effective than a placebo in eradication of BV in pregnant women (39).

Some treatment failures may be due to concomitant yeast vaginitis (161).

\section{Clindamycin}

Because there are treatment failures and side effects (metallic taste and gastrointestinal upset) with metronidazole (47), and because it cannot be used in early pregnancy owing to its teratogenicity, alternative therapeutic agents have been sought. Oral clindamycin has been evaluated because of its activity against anaerobic bacteria and $G$. vaginalis (59). The failure rates for metronidazole (4\%) and clindamycin $(6 \%)$ were similar at 7 to 10 days following initiation of therapy. A 4-week follow-up examination is necessary to determine adequately the rate of persistence. Three patients in the clindamycin group and none in the metronidazole group developed nonbloody diarrhea. The cause of diarrhea was not determined, but one can speculate that it may have been due to Clostridium difficile.

Intravaginal clindamycin cream has also been evaluated $(76,120)$. Five grams of $0.1,1.0$, or $2.0 \%$ clindamycin cream administered intravaginally morning and night for $5(120)$ or 7 (76) consecutive days effected a cure significantly more often than placebo in women examined 4 to 7 days after completion of therapy. Ninety percent of the cured patients and $75 \%$ of the cured controls were still free of $\mathrm{BV}$ at a 1-month follow-up examination. Patients who responded clinically usually had a normal vaginal fluid Gram stain, suggesting that lactobacilli were able to recolonize despite this therapy (120). One study detected no difference in efficacy among the concentrations of clindamycin tested (120), and the other found that patients treated with $2 \%$ cream had a lower recurrence rate $(6 \%) 1$ month after completion of therapy than women who received a lower dosage $(29 \% ; P=0.13)$. Clindamycin cream may be an acceptable alternative therapy for BV, especially for women who cannot take metronidazole because of adverse side effects or because of pregnancy or who fail therapy with it.

\section{Lactate Gel}

There has been a recent resurgence of interest in lactate gel for therapy of BV. This product contains lactic acid and growth substrates for lactobacilli buffered at $\mathrm{pH} 3.5$ to 3.8. It was as effective as oral metronidazole at a 1-week follow-up
(3). Monthly treatments after completion of menstrual bleeding for 6 consecutive months eradicated BV in 15 of 17 patients and 1 of 10 controls given placebo who completed the trial (4). The placebo gel was unbuffered, unlike the carrier for the lactate gel. The women who responded were not studied after the monthly treatments had been discontinued. Reappearance of a lactobacillus-dominated flora was seen in 10 pregnant women treated intermittently with lactate gel (84). Further study of this product or others that would lower the vaginal fluid $\mathrm{pH}$ are warranted.

\section{Other}

Tetracycline, although active against $G$. vaginalis, is not an effective therapy for BV, probably because of its poor anaerobic activity (222). Triple sulfa cream, formerly a widely accepted therapeutic agent for $\mathrm{BV}$, had no greater activity than a placebo control (152). Erythromycin is inactive at the $\mathrm{pH}$ of vaginal fluid (43).

Recolonization of the vagina by intravaginal administration of hydrogen peroxide-producing lactobacilli may be possible, but current over-the-counter products do not appear to be appropriate (90).

\section{CONCLUSION}

A great deal more is known about BV in 1991 than was understood in 1955 or 1980 . Our tendency in examining a new disease is to attempt to find a single pathogen with which we can fulfill Koch's postulates. BV has been resistant to that approach. Rather, BV appears to be due to an alteration in the endogenous flora. BV-associated organisms that are part of the endogenous vaginal flora, such as Prevotella bivia, P. disiens, Prevotella spp., Peptostreptococcus spp., G. vaginalis, Mycoplasma hominis, and Mobiluncus spp., which may reside in the rectum, become dominant. In addition, hydrogen peroxide-producing Lactobacillus spp. are significantly reduced. However, we do not know which of these alterations occurs first and what stimulates them. These changes can be recognized by cultural, microscopic, and chemical examination of the vagina. Some episodes of BV may be sexually transmitted and others may not. In some cases, the pathogenesis of BV may be like that of urinary tract infections: rectal organisms may gain access to the vagina.

That the presence of BV puts the patient at increased risk of upper genital tract infection, with severe consequences to fertility and outcome of pregnancy, is an extremely important recent finding.

There is still much to learn about BV. Areas for further research on BV include diagnosis, pathogenesis, and therapy. The availability of a rapid nonmicroscopic test that would allow accurate diagnosis of $\mathrm{BV}$ in diverse settings would be beneficial. Further studies on the utility of the Pap smear for diagnosis of BV are also warranted. Studies to determine the reservoir of the BV-associated flora and the modes by which the organisms are acquired and transmitted are needed, as are studies on the interactions among the flora. An animal model would be extremely useful for the latter $(100,123)$. The source(s) of amines is yet to be determined. The characteristics of women who experience spontaneous remission of BV and the characteristics of their vaginal flora also require study. The role in BV played by changes in the vaginal environment as it responds to hormonal changes throughout the menstrual cycle are warranted. Additional treatment studies must include methods 
to prevent pregnancy complications and treat $\mathrm{BV}$ in nonpregnant women. Studies in which hydrogen peroxide-producing lactobacilli are used either as a prophylaxis or as a treatment for BV are now appropriate.

The 1990s hold greater promise for increasing our understanding of BV than was realized in the $1980 \mathrm{~s}$.

\section{REFERENCES}

1. Amsel, R., C. W. Critchlow, C. A. Spiegel, K. C. S. Chen, D. A. Eschenbach, K. Smith, and K. K. Holmes. 1982. Comparison of metronidazole, ampicillin, and amoxicillin for treatment of bacterial vaginosis (nonspecific vaginitis): possible explanation for the greater efficacy of metronidazole, p. 225-237. In S. M. Finegold (ed.), U.S. Metronidazole Conference, proceedings from a symposium. Biomedical Information Corp., New York.

2. Amsel, R., P. A. Totten, C. A. Spiegel, K. C. S. Chen, D. Eschenbach, and K. K. Holmes. 1983. Nonspecific vaginitis: diagnostic criteria and microbial and epidemiologic associations. Am. J. Med. 74:14-22.

3. Andersch, B., L. Forssman, K. Lincoln, and P. Torstensson. 1986. Treatment of bacterial vaginosis with an acid cream: a comparison between the effect of lactate-gel and metronidazole. Gynecol. Obstet. Invest. 21:19-25.

4. Andersch, B., D. Lindell, I. Dahlén, and Å. Brandberg. 1990. Bacterial vaginosis and the effect of intermittent prophylactic treatment with acid lactate gel. Gynecol. Obstet. Invest. 30: 114-119.

5. Avonts, D., M. Sercu, P. Heyerick, I. Vandermeeren, A. Meheus, and P. Piot. 1990. Incidence of uncomplicated genital infections in women using oral contraception or an intrauterine device: a prospective study. Sex. Transm. Dis. 17:23-29.

6. Bailey, R. K., J. L. Voss, and R. F. Smith. 1979. Factors affecting isolation and identification of Haemophilus vaginalis (Corynebacterium vaginale). J. Clin. Microbiol. 9:65-71.

7. Balsdon, M. J., G. E. Taylor, L. Pead, and R. Maskell. 1980. Corynebacterium vaginale and vaginitis: a controlled trial of treatment. Lancet i:501-504.

8. Barbone, F., H. Austin, W. C. Louv, and W. J. Alexander. 1990. A follow-up study of methods of contraception, sexual activity, and rates of trichomoniasis, candidiasis, and bacterial vaginosis. Am. J. Obstet. Gynecol. 163:510-514.

9. Bartlett, J. G., N. E. Moon, P. R. Goldstein, B. Goren, A. B. Onderdonk, and B. F. Polk. 1978. Cervical and vaginal bacterial flora: ecologic niches in the female lower genital tract. Am. J. Obstet. Gynecol. 130:658-661.

10. Bartlett, J. G., A. B. Onderdonk, E. Drude, C. Goldstein, M. Anderka, S. Alpert, and W. M. McCormack. 1977. Quantitative bacteriology of the vaginal flora. J. Infect. Dis. 136:271-278.

11. Bayer, A. S., A. W. Chow, N. Concepcion, and L. B. Guze. 1978. Susceptibility of 40 lactobacilli to six antimicrobial agents with broad gram-positive anaerobic spectra. Antimicrob. Agents Chemother. 14:720-722.

12. Bejar, R., V. Curbelo, C. Davis, and L. Cluck. 1981. Premature labor. II. Bacterial sources of phospholipase. Obstet. Gynecol. $57: 479-482$.

13. Benito, R., J. A. Vazquez, S. Berron, A. Fenoll, and J. A. Saez-Nieto. 1986. A modified scheme for biotyping Gardnerella vaginalis. J. Med. Microbiol. 21:357-359.

14. Bennett, K. W., T. G. Winstanley, A. K. M. Taylor, and A. J. Shorthouse. 1989. Anaerobic curved rods in breast abscess and vagina. Lancet i:564. (Letter.)

15. Bistoletti, P., B. Fredericsson, B. Hagstrom, and C.-E. Nord. 1986. Comparison of oral and vaginal metronidazole therapy for nonspecific bacterial vaginosis. Gynecol. Obstet. Invest. 21:144-149.

16. Blackwell, A., and D. Barlow. 1982. Clinical diagnosis of anaerobic vaginosis (non-specific vaginitis). $\mathrm{Br}$. J. Vener. Dis. 58:387-393.

17. Blackwell, A. L., A. R. Fox, I. Phillips, and D. Barlow. 1983. Anaerobic vaginosis (non-specific vaginitis): clinical, microbiological, and therapeutic findings. Lancet ii:1379-1382.

18. Botta, G. A., C. Eftimiadi, A. Costa, M. Tonetti, T. J. M. van
Steenbergen, and J. deGraff. 1985. Influence of volatile fatty acids on human granulocyte chemotaxis. FEMS Microbiol. Lett. 27:69-72.

19. Boustouller, Y. L., A. P. Johnson, and D. Taylor-Robinson. 1987. Pili on Gardnerella vaginalis studied by electronmicroscopy. J. Med. Microbiol. 23:327-329.

20. Brand, J. M., and R. P. Galask. 1986. Trimethylamine: the substance mainly responsible for the fishy odor often associated with bacterial vaginosis. Obstet. Gyneol. 68:682-685.

21. Bratos, M. A., A. Orduña, J. Medina, R. O. de Lejarazu, and A. Rodriguez-Torres. 1984. Diagnosis of Gardnerella vaginalis infection by an enzyme-linked immunosorbent assay. Eur. J. Clin. Microbiol. 5:46-48.

22. Briselden, A. M., and S. L. Hillier. 1990. Longitudinal study of the biotypes of Gardnerella vaginalis. J. Clin. Microbiol. 28:2761-2764

23. Brown, W. J. 1978. Microbial ecology of the normal vagina, p. 407-422. In E. S. E. Hafez and T. N. Evans (ed.), The human vagina. North-Holland Publishing Co., Amsterdam.

24. Bump, R. C., and W. J. I. Buesching. 1988. Bacterial vaginosis in virginal and sexually active adolescent females: evidence against exclusive sexual transmission. Am. J. Obstet. Gynecol. 158:935-939.

25. Bump, R. C., F. P. Zuzpan, W. J. Buesching, L. W. Ayers, and T. J. Stephens. 1984. The prevalence, six-month persistence, and predictive values of laboratory indicators of bacterial vaginosis (nonspecific vaginitis) in asymptomatic women. Am. J. Obstet. Gynecol. 150:917-924.

26. Cano, R. J., M. A. Beck, and D. V. Grady. 1983. Detection of Gardnerella vaginalis in vaginal smears by immunofluorescence. Can. J. Microbiol. 29:27-32.

27. Carlone, G. M., M. L. Thomas, R. J. Arko, G. O. Guerrant, C. W. Moss, J. M. Swenson, and S. A. Morse. 1986. Cell wall characteristics of Mobiluncus species. Int. J. Syst. Bacteriol. 36:288-296.

28. Chen, K. C. S., R. Amsel, D. A. Eschenbach, and K. K. Holmes. 1982. Biochemical diagnosis of vaginitis: determination of diamines in vaginal fluid. J. Infect. Dis. 145:337-345.

29. Chen, K. C. S., P. S. Forsyth, T. M. Buchanan, and K. K. Holmes. 1979. Amine content of vaginal fluid from untreated and treated patients with non-specific vaginitis. J. Clin. Invest. 63:825-835.

30. Christiansen, G., E. Holst, L. Larsson, P.-A. Mårdh, and A. Skarin. 1984. Subdivision of vaginal isolates of anaerobic curved bacteria based on genetic, morphologic, biochemical and gas chromatographic/mass spectrometric studies. Scand. J. Urol. Nephrol. Suppl. 86:241-250.

31. Cook, R. L., G. Reid, D. G. Pond, C. A. Schmidt, and J. D. Sobel. 1989. Clue cells in bacterial vaginosis: immunofluorescent identification of adherent gram-negative bacteria as Gard nerella vaginalis. J. Infect. Dis. 160:490-496.

32. Cristiano, L., N. Coffetti, G. Dalvai, L. Lorasso, and $M$. Lorenzi. 1989. Bacterial vaginosis: prevalence in outpatients, association with some micro-organisms and laboratory indices. Genitourin. Med. 65:382-387.

33. Criswell, B. S., J. H. Marston, W. A. Stenback, S. H. Black, and H. L. Gardner. 1971. Haemophilus vaginalis 594, a gramnegative organism? Can. J. Microbiol. 17:865-869.

34. Cruden, D. L., and R. P. Galask. 1988. Reduction of trimethylamine oxide to trimethylamine by Mobiluncus strains isolated from patients with bacterial vaginosis. Microb. Ecol. Health Dis. 1:95-100.

35. Cruickshank, R., and A. Sharman. 1934. The biology of the vagina in the human subject. J. Obstet. Gynaecol. Br. Emp. 41:208-226.

36. Csángó, P. A., N. Hagen, and G. Jagars. 1982. Method for isolation of Gardnerella vaginalis (Haemophilus vaginalis): characterization of isolates by gas chromatography. Acta Pathol. Microbiol. Scand. Sect. B. 90:89-93.

37. Curtis, A. H. 1913. A motile curved anaerobic bacillus in uterine discharges. J. Infect. Dis. 12:165-169.

38. deBoer, J. M., and F. H. F. Plantema. 1988. Ultrastructure of the in situ adherence of Mobiluncus to the vaginal epithelial 
cells. Can. J. Microbiol. 34:757-766.

39. Duff, P., M. L. Lee, S. L. Hillier, L. M. Herd, M. A. Krohn, and D. A. Eschenbach. 1991. Amoxicillin treatment of bacterial vaginosis during pregnancy. Obstet. Gynecol. 77:431-435.

40. Dunkelberg, W. E. 1965. Diagnosis of Haemophilus vaginalis vaginitis by gram-stained smears. Am. J. Obstet. Gynecol. 91:998-1000.

41. Dunkelberg, W. E., Jr., R. Skaggs, and D. S. Kellogg, Jr. 1970. Method for isolation and identification of Corynebacterium vaginale (Haemophilus vaginalis). Am. J. Clin. Pathol. 19:4752.

42. Durieux, R., and A. Dublanchet. 1980. Les "Vibrions" anaérobies des leucorrhées, I. Technique d'isolement et sensibilité aux antibiotiques. Med. Malad. Infect. 10:109-115.

43. Durfee, M. A., P. S. Forsyth, J. A. Hale, and K. K. Holmes. 1979. Ineffectiveness of erythromycin for treatment of Haemophilus vaginalis-associated vaginitis: possible relationship to acidity of vaginal secretions. Antimicrob. Agents Chemother. 16:635-637.

44. Edelman, D. A., and B. B. North. 1989. Treatment of bacterial vaginosis with intravaginal sponges containing metronidazole. J. Reprod. Med. 34:341-344.

45. Edmiston, C. E., C. J. Krepel, and A. P. Walker. 1989. Recovery of Mobiluncus curtisii subspecies holmesii from mixed non-puerperal breast abscess. Eur. J. Clin. Microbiol. Infect. Dis. 8:315-316. (Letter.)

46. Eschenbach, D. A., T. M. Buchanan, H. M. Pollock, P. S. Forsyth, E. R. Alexander, J.-S. Lin, S.-P. Wang, B. B. Wentworth, W. M. McCormack, and K. K. Holmes. 1973. Polymicrobial etiology of acute pelvic inflammatory disease. N. Engl. J. Med. 293:166-171.

47. Eschenbach, D. A., C. W. Critchlow, H. Watkins, K. Smith, C. A. Spiegel, K. C. S. Chen, and K. K. Holmes. 1983. A dose-duration study of metronidazole for the treatment of nonspecific vaginosis. Scand. J. Infect. Dis. Suppl. 40:73-80.

48. Eschenbach, D. A., P. R. Davick, B. L. Williams, S. J. Klebanoff, K. Young-Smith, C. M. Critchlow, and K. K. Holmes. 1989. Prevalence of hydrogen peroxide-producing Lactobacillus species in normal women and women with bacterial vaginosis. J. Clin. Microbiol. 27:251-256.

49. Eschenbach, D. A., S. Hillier, C. Critchlow, C. Stevens, T. DeRousen, and K. K. Holmes. 1988. Diagnosis and clinical manifestations of bacterial vaginosis. Am. J. Obstet. Gynecol. 158:819-828.

50. Fohn, M. J., S. A. Lukehart, and S. L. Hillier. 1988. Production and characterization of monoclonal antibodies to Mobiluncus species. J. Clin. Microbiol. 26:2598-2603.

51. Fredericsson, B., B. Hagström, G. Evaldson, and C.-E. Nord. 1984. Gardnerella-associated vaginitis and anaerobic bacteria. Gynecol. Obstet. Invest. 17:236-241.

52. Gardner, H. L., and C. D. Dukes. 1955. Haemophilus vaginalis vaginitis. A newly defined specific infection previously classified "nonspecific" vaginitis. Am. J. Obstet. Gynecol. 69:962976.

53. Glupczynski, Y., M. Labbé, F. Crokaert, F. Pepersack, P. van der Auwera, and E. Yourassowsky. 1984. Isolation of Mobiluncus in four cases of extragenital infections in adult women. Eur. J. Clin. Microbiol. 3:433-435.

54. Goldacre, M. J., B. Watt, N. Loudon, L. J. R. Milne, J. D. O. Loucon, and M. P. Vessey. 1979. Vaginal microbial flora in normal young women. Br. Med. J. 1:1450-1453.

55. Goplerud, C. P., M. J. Ohm, and R. P. Galask. 1976. Aerobic and anaerobic flora of the cervix during pregnancy and the puerperium. Am. J. Obstet. Gynecol. 126:858-865.

56. Gorbach, S. L., K. B. Menda, H. Thadepalli, and L. Keith. 1973. Anaerobic microflora of the cervix in healthy women. Am. J. Obstet. Gynecol. 117:1053-1055.

57. Gravett, M. G., D. Hummel, D. A. Eschenbach, and K. K. Holmes. 1986. Preterm labor associated with subclinical amniotic fluid infection and with bacterial vaginosis. Obstet. Gynecol. 67:229-237.

58. Gravett, M. G., H. P. Nelson, T. DeRouen, C. Critchlow, D. A. Eschenbach, and K. K. Holmes. 1986. Independent associations of bacterial vaginosis and Chlamydia trachomatis infection with adverse pregnancy outcome. J. Am. Med. Assoc. 256: 1899-1903.

59. Greaves, W. L., J. Chungagung, B. Morris, A. Haile, and J. L. Townsend. 1988. Clindamycin versus metronidazole in the treatment of bacterial vaginosis. Obstet. Gynecol. 72:799-802.

60. Greenwood, J. R., and M. J. Pickett. 1979. Salient features of Haemophilus vaginalis. J. Clin. Microbiol. 9:200-204.

61. Greenwood, J. R., and M. J. Pickett. 1980. Transfer of Haemophilus vaginalis Gardner and Dukes to a new genus, Gardnerella: G. vaginalis (Gardner and Dukes) comb. nov. Int. J. Syst. Bacteriol. 30:170-178.

62. Greenwood, J. R., and M. J. Pickett. 1986. Genus Gardnerella Greenwood and Pickett 1980, p. 1283-1286. In P. H. A. Sneath (ed.), Bergey's manual of determiniative bacteriology, 9th ed., vol. 2. The Williams \& Wilkins Co., Baltimore.

63. Greenwood, J. R., M. J. Pickett, W. J. Martin, and E. G. Mack. 1977. Haemophilus vaginalis (Corynebacterium vaginale): method for isolation and rapid biochemical identification. Health Lab. Sci. 14:102-106.

64. Hallén, A., C. Påhlson, and U. Forsum. 1988. Rectal occurrence of Mobiluncus species. Genitourin. Med. 64:273-275.

65. Hammann, R., A. Kronibus, N. Lang, and H. Werner. 1986. Quantitative studies on the vaginal flora of asymptomatic women and patients with vaginitis and vaginosis. Zentralbl. Bakteriol. Hyg. A. 265:451-461.

66. Hammann, R., A. Kronibus, A. Viebahn, and H. Brandis. 1984. Falcivibrio grandis gen. nov. sp. nov., and Falcivibrio vaginalis gen. nov. sp. nov., a new genus and species to accomodate anaerobic motile curved rods formerly described as "Vibrio mulieris" (Prévot 1940) Breed et al. 1948. Syst. Appl. Microbiol. 5:81-96.

67. Hammerschlag, M. R., S. Alpert, A. B. Onderdonk, P. Thurston, E. Drude, W. M. McCormack, and J. G. Bartlett. 1978. Anaerobic microflora of the vagina in children. Am. J. Obstet. Gynecol. 131:853-856.

68. Hammerschlag, M. R., S. Alpert, I. Rosner, P. Thurston, D. Semine, D. McComb, and W. M. McCormack. 1978. Microbiology of the vagina in children: normal and potentially pathogenic organisms. Pediatrics 62:57-62.

69. Hansen, W., B. Vray, K. Miller, F. Crokaert, and E. Yourassowsky. 1987. Detection of Gardnerella vaginalis in vaginal specimens by direct immunofluorescence. J. Clin. Microbiol. 25:1934-1937.

70. Harper, J. J., and G. H. G. Davis. 1982. Cell wall analysis of Gardnerella (Haemophilus vaginalis). Int. J. Syst. Bacteriol. 32:48-50.

71. Heisterberg, L., P. E. Branebjerg, A. Bremmelgaard, J. Scheibel, and L. Høj. 1987. The role of vaginal secretory immunoglobulin A, Gardnerella vaginalis, anaerobes, and Chlamydia trachomatis in postabortal pelvic inflammatory disease. Acta Obstet. Gynecol. Scand. 66:99-102.

72. Hill, G. B., and O. M. Ayers. 1985. Antimicrobial susceptibilities of anaerobic bacteria isolated from female genital tract infections. Antimicrob. Agents Chemother. 27:324-331.

73. Hill, G. B., D. A. Eschenbach, and K. K. Holmes. 1984. Bacteriology of the vagina. Scand. J. Urol. Nephrol. Suppl. 86:23-39.

74. Hill, L. V. H., and J. A. Embil. 1986. Vaginitis: current microbiologic and clinical concepts. Can. Med. Assoc. J. 134:321-331.

75. Hillier, S. L., M. A. Krohn, and D. A. Eschenbach. 1987. Program Abstr. 7th Int. Soc. Sex. Transm. Dis. Res., abstr. 55, p. 55 .

76. Hillier, S., M. A. Krohn, H. Watts, P. Wolner-Hanssen, and D. Eschenbach. 1990. Microbiological efficacy of intravaginal clindamycin cream for the treatment of bacterial vaginosis. Obstet. Gynecol. 76:407-413.

77. Hillier, S. L., J. Martius, M. Krohn, N. Kiviat, K. K. Holmes, and D. A. Eschenbach. 1988. A case-control study of chorioamnionic infection and histologic chorioamnionitis in prematurity. N. Engl. J. Med. 319:927-978.

78. Hjelm, E., A. Hallén, U. Forsum, and J. Wallin. 1981. Anaer- 
obic curved rods in vaginitis. Lancet ii:1353-1354.

79. Hjelm, E., A. Hallén, U. Forsum, and J. Wallin. 1982. Motile anaerobic curved rods in non-specific vaginitis. Eur. J. Sex. Transm. Dis. 1:9-14.

80. Holdeman, L. V., E. P. Cato, and W. E. C. Moore (ed.). 1977. Anaerobe laboratory manual, 4th ed. Virginia Polytechnic Institute and State University, Blacksburg.

81. Holmes, K. K., K. C. S. Chen, C. M. Lipinski, and D. A. Eschenbach. 1985. Vaginal redox potential in bacterial vaginosis (nonspecific vaginitis). J. Infect. Dis. 152:379-382.

82. Holmes, K. K., C. Spiegel, R. Amsel, D. A. Eschenbach, K. C. S. Chen, and P. Totten. 1981. Nonspecific vaginosis. Scand. J. Infect. Dis. Suppl. 26:110-114.

83. Holst, E. 1990. Reservoir of four organisms associated with bacterial vaginosis suggests lack of sexual transmission. J. Clin. Microbiol. 28:2035-2039.

84. Holst, E., and $\AA$. Brandberg. 1990. Treatment of bacterial vaginosis in pregnancy with a lactate gel. Scand. J. Infect. Dis. 22:625-626.

85. Holst, E., H. Hofmann, and P.-A. Mårdh. 1984. Anaerobic curved rods in genital samples of women. Scand. J. Urol. Nephrol. Suppl. 86:117-124.

86. Holst, E., P.-A. Mårdh, and I. Thelin. 1984. Recovery of anaerobic curved rods and Gardnerella vaginalis from the urethra of men, including male homosexual consorts of female carriers. Scand. J. Urol. Nephrol. Suppl. 86:173-177.

87. Holst, E., A. Skarin, and P.-A. Mårdh. 1982. Characteristics of anaerobic comma-shaped bacteria recovered from the female genital tract. Eur. J. Clin. Microbiol. 1:310-316.

88. Holst, E., B. Wathne, B. Hovelius, and P.-A. Mårdh. 1987. Bacterial vaginosis: microbiological and clinical findings. Eur. J. Clin. Microbiol. 6:536-541.

89. Hooton, T. M., S. D. Finn, C. Johnson, P. L. Roberts, and W. E. Stamm. 1989. Association between bacterial vaginosis and acute cystitis in women using diaphragms. Ann. Intern. Med. 149:1932-1936.

90. Hughes, V. L., and S. L. Hillier. 1990. Microbiologic characteristics of Lactobacillus products used for colonization of the vagina. Obstet. Gynecol. 75:244-248.

91. Human, R. P., and G. S. Tillotson. 1985. Identification of Gardnerella vaginalis with the API20 Strep strip. J. Clin. Microbiol. 21:985-986.

92. Hunter, C. A., and K. R. Long. 1958. A study of the microbiological flora of the human vagina. Am. J. Obstet. Gynecol. 75:865-871.

93. Huth, E. J. 1989. Bacterial vaginosis or vaginal bacteriosis? Ann. Intern. Med. 111:553-554.

94. Ison, C. A. 1990 . Factors affecting the microflora of the lower genital tract of healthy women, p. 111-130. In M. J. Hill and P. D. March (ed.), Human microbial ecology. CRC Press, Boca Raton, Fla.

95. Ison, C. A., S. G. Dawson, J. Hilton, G. W. Csonka, and C. S. F. Easmon. 1982. Comparison of culture and microscopy in the diagnosis of Gardnerella vaginalis infection. J. Clin. Pathol. 35:550-554.

96. Ison, C. A., C. S. F. Easmon, S. G. Dawson, G. Southerton, and J. W. R. Harris. 1983. Non-volatile fatty acids in the diagnosis of non-specific vaginitis. J. Clin. Pathol. 36:1367-1370.

97. Ison, C. A., D. G. Harvey, A. Tanna, and C. S. F. Easmon. 1987. Development and evaluation of scheme for serotyping Gardnerella vaginalis. Genitourin. Med. 63:196-201.

98. Ison, C. A., B. Kolator, J. H. Reid, E. Dermott, J. Clark, and C. S. F. Easmon. 1989. Characterization of monoclonal antibodies for detection of Mobiluncus spp. in genital specimens. J. Med. Microbiol. 30:129-136.

99. Johnson, A. P., and H. A. Davies. 1984. Demonstration by electron microscopy of pili on Gardnerella vaginalis. $\mathrm{Br}$. J. Vener. Dis. 60:396-397.

100. Johnson, A. P., C. A. Ison, C. M. Hetherington, M. F. Osborn, G. Southerton, W. T. London, C. S. F. Easmon, and D. Taylor-Robinson. 1984. Vaginal colonization of pig-tailed macaques by Gardnerella vaginalis. Scand. J. Urol. Nephrol. Suppl. 86:207-212.
101. Johnson, S. R., C. R. Petzold, and R. P. Galask. 1985. Qualitative and quantitative changes of the vaginal microflora during the menstrual cycle. Am. J. Reprod. Immunol. Microbiol. 9:1-5.

102. Johnston, M. M., L. Sanchez-Ramos, A. J. Vaughn, M. W. Todd, and G. I. Benrubi. 1990. Antibiotic therapy in preterm premature rupture of membranes: a randomized, prospective, double-blind trial. Am. J. Obstet. Gynecol. 163:743-747.

103. Jokipii, A. M. M., L. Jokipii, E. Vesterinen, E. Purola, E. Vartiainen, and J. Paavonen. 1986. Volatile fatty acid findings in vaginal fluid compared with symptoms, signs and other laboratory results, and susceptibility to tinidazole of malodorous vaginal discharges. Genitourin. Med. 62:102-106.

104. Jolly, J. L. S. 1983. Minimal criteria for the identification of Gardnerella vaginalis isolated from the vagina. J. Clin. Pathol. 36:476-478.

105. Kamio, Y., and K. Nakamura. 1987. Putrescine and cadaverine are constituents of peptidoglycan in Veillonella alcalescens and Veillonella parvula. J. Bacteriol. 169:2881-2884.

106. Kivijärvi, A., H. Järvinen, and M. Grönroos. 1984. Microbiology of vaginitis associated with the intrauterine contraceptive device. Br. J. Obstet. Gynecol. 91:917-923.

107. Klebanoff, S. J., S. L. Hillier, D. A. Eschenbach, and A. M. Waltersdorph. 1990. Control of the microbial flora of the vagina by $\mathrm{H}_{2} \mathrm{O}_{2}$-generating lactobacilli. J. Infect. Dis. 164:94-100.

108. Kotcher, E. 1967. Microbiological considerations in pediatric and adolescent gynecology. Ann. N.Y. Acad. Sci. 142:586591.

109. Koutsky, L. A., W. E. Stamm, R. C. Brunham, C. E. Stevens, B. Cole, J. Hale, P. Davick, and K. K. Holmes. 1983. Persistence of Mycoplasma hominis after therapy: importance of tetracycline resistance and of coexisting vaginal flora. Sex. Transm. Dis. Suppl. 11:374-381.

110. Krohn, M. A., S. L. Hillier, and D. A. Eschenbach. 1989. Comparison of methods for diagnosing bacterial vaginosis among pregnant women. J. Clin. Microbiol. 27:1266-1271.

111. Krohn, M. A., S. L. Hillier, M. L. Lee, L. K. Rabe, and D. A. Eschenbach. 1991. Vaginal Bacteroides species are associated with an increased rate of preterm delivery among women in preterm labor. J. Infect. Dis. 164:88-93.

112. Krönig, I. 1895. Über die Natur der Scheidenheme, speciell über das vorkommen anaërober Streptokokken in Scheidensekret Schwangerer. Centralbl. Gynaecol. 19:409-412.

113. Lacroix, J.-M., F. Lamothe, and F. Malouin. 1984. Role of Bacteroides bivius $\beta$-lactamase in $\beta$-lactam susceptibility. Antimicrob. Agents Chemother. 26:694-698.

114. Larsen, B., C. P. Goplerud, C. R. Petzold, M. J. Ohm-Smith, and R. P. Galask. 1982. Effect of estrogen treatment on the genital tract flora of postmenopausal women. Obstet. Gynecol. 60:20-24.

115. Larsson, P.-G., and B. B. Bergman. 1986. Is there a causa connection between motile curved rods, Mobiluncus species, and bleeding complications? Am. J. Obstet. Gynecol. 154:107108 .

116. Larsson, P.-G., B. Bergman, U. Forsum, and C. Påhlson. 1990 Treatment of bacterial vaginosis in women with vaginal bleeding complications or discharge and harboring Mobiluncus. Gynecol. Obstet. Invest. 29:296-300.

117. Lefèvre, J. C., S. Averous, R. Bauriaud, C. Blanc, M. A. Bertrana, and M. B. Lareng. 1988. Lower genital tract infections in women: comparison of clinical and epidemiological findings with microbiology. Sex. Transm. Dis. 15:110-113.

118. Leopold, S. 1953. Heretofore undescribed organism isolated from genitourinary system. U.S. Armed Forces Med. J. 4:263266.

119. Levison, M. E., I. Trestman, R. Quach, C. Sladowski, and C. N. Floro. 1979. Quantitative bacteriology of the vaginal flora in vaginitis. Am. J. Obstet. Gynecol. 133:139-144.

120. Livengood, C. H., J. L. Thomason, and G. B. Hill. 1990. Bacterial vaginosis: treatment with topical intravaginal clindamycin phosphate. Obstet. Gynecol. 76:118-123.

121. Lossick, J. G. 1990. Treatment of sexually transmitted vaginitis/vaginosis. Rev. Infect. Dis. 12(Suppl. 6):S665-S681. 
122. Malone, B. H., M. Schreiber, N. J. Schneider, and L. V. Holdeman. 1975. Obligately anaerobic strains of Corynebacterium vaginale (Haemophilus vaginalis). J. Clin. Microbiol. 2:272-275.

123. Mårdh, P.-A., E. Holst, and B. R. Möeller. 1984. The grivet monkey as a model for study of vaginitis. Challenge with anaerobic curved rods and Gardnerella vaginalis. Scand. J. Urol. Nephrol. Suppl. 86:201-206.

124. Mårdh, P.-A., and L. V. Soltész. 1983. In vitro interactions between Lactobacillus and other microorganisms occurring in the vaginal flora. Scand. J. Infect. Dis. Suppl. 40:47-51.

125. Martius, J., and D. A. Eschenbach. 1990. The role of bacterial vaginosis as a cause of amniotic fluid infection, chorioamnionitis and prematurity-a review. Arch. Gynecol. Obstet. 247:113.

126. Martius, J., M. A. Krohn, S. L. Hillier, W. E. Stamm, K. K. Holmes, and D. A. Eschenbach. 1988. Relationships of vaginal Lactobacillus species, cervical Chlamydia trachomatis, and bacterial vaginosis to preterm birth. Obstet. Gynecol. 71:8995.

127. Mazzulli, T., A. E. Simor, and D. E. Low. 1990. Reproducibility of interpretation of Gram-stained vaginal smears for the diagnosis of bacterial vaginosis. J. Clin. Microbiol. 28:15061508 .

128. McCarthy, L. R., P. A. Mickelsen, and E. G. Smith. 1979. Antibiotic susceptibility of Haemophilus vaginalis (Corynebacterium vaginale) to 21 antibiotics. Antimicrob. Agents Chemother. 16:186-189.

129. McCormack, W. M., C. H. Hayes, B. Rosner, J. R. Evrard, V. A. Crockett, S. Alpert, and S. H. Zinner. 1977. Vaginal colonization with Corynebacterium vaginale (Haemophilus vaginalis). J. Infect. Dis. 136:740-745.

130. McGregor, J. A., and J. I. French. 1988. Are neonatal scalp abscesses another complication of bacterial vaginosis? Pediatr. Infect. Dis. J. 7:437-438.

131. McGregor, J. A., J. I. French, R. Richter, M. Vuchetich, V. Bachus, K. Seo, S. Hillier, F. N. Judson, J. McFee, J. Schoonmaker, and J. K. Todd. 1990. Cervicovaginal microflora and pregnancy outcome: results of a double-blind, placebo controlled trial of erythromycin treatment. Am. J. Obstet. Gynecol. 163:1580-1591.

132. Mengel, M. B., A. O. Berg, C. H. Weaver, D. J. Herman, S. J. Herman, V. L. Hughes, T. D. Koepsell, and B. V. S. Group. 1988. The effectiveness of single-dose metronidazole therapy for patients and their partners with bacterial vaginosis. J. Fam. Practice 28:163-171.

133. Miettinen, A. 1987. Mycoplasma hominis in patients with pelvic inflammatory disease. Isr. J. Med. Sci. 23:713-716.

134. Miettinen, A., P. K. Heinonen, K. Teisala, K. Hakkarainen, and R. Punnonen. 1990. Serologic evidence for the role of Chlamydia trachomatis, Neisseria gonorrhoeae, and Mycoplasma hominis in the etiology of tubal factor infertility and ectopic pregnancy. Sex. Transm. Dis. 17:10-19.

135. Moberg, P., P. Eneroth, J. Harlin, Å. Ljung-Wadström, and C.-E. Nord. 1978. Cervical bacterial flora in infertile and pregnant women. Med. Microbiol. Immunol. 165:139-145.

136. Moi, H., D. Danielsson, and F. Schoenknecht. 1984. An in vitro study of the attachment to vaginal epithelial cells of anaerobic curved rods, Bacteroides bivius and Bacteroides disiens. Scand. J. Urol. Nephrol. Suppl. 86:185-190.

137. Moi, H., R. Erkkola, F. Jerve, G. Nelleman, B. Bymose, K. Alaksen, and E. Tornqvist. 1989. Should male consorts of women with bacterial vaginosis be treated? Genitourin. Med. 675:263-268.

138. Moi, H., F. Schoenknecht, E. Tornqvist, and D. Danielsson. 1984. A serological study of anaerobic curved rods with rabbit hyperimmune antisera. Scand. J. Urol. Nephrol. Suppl. 86:7988.

139. Moore, B. 1954. Observations on a group of anaerobic vaginal vibrios. J. Pathol. Bacteriol. 67:461-473.

140. Nord, C. E., and B. Olsson-Liljequist. 1984. Antimicrobial susceptibility of anaerobic bacteria in Sweden in 1984. Scand. J. Infect. Dis. Suppl. 43:44-49.
141. Nugent, R. P., M. A. Krohn, and S. L. Hillier. 1991. Reliability of diagnosing bacterial vaginosis is improved by a standardized method of Gram stain interpretation. J. Clin. Microbiol. 29: 297-301.

142. Onderdonk, A. B., B. F. Polk, N. E. Moon, B. Goren, and J. G. Bartlett. 1977. Methods for quantitative vaginal flora studies. Am. J. Obstet. Gynecol. 128:777-781.

143. Onderdonk, A. B., G. R. Zamarchi, J. A. Walsh, R. D. Mellor, A. Muñoz, and E. H. Kass. 1986. Methods for quantitative and qualitative evaluation of vaginal microflora during menstruation. Appl. Environ. Microbiol. 51:333-339.

144. Osborne, N. G., R. C. Wright, and L. Grubin. 1979. Genita bacteriology: a comparative study of premenopausal women with postmenopausal women. Am. J. Obstet. Gynecol. 135: 195-198.

145. Paavonen, J., A. Miettinen, C. E. Stevens, K. C. S. Chen, and K. K. Holmes. 1983. Mycoplasma hominis in nonspecific vaginitis. Sex. Transm. Dis. Suppl. 10:271-275.

146. Påhlson, C., and U. Forsum. 1985. Rapid detection of Mobiluncus species. Lancet i:927. (Letter.)

147. Påhlson, C., A. Hallen, and U. Forsum. 1986. Improved yield of Mobiluncus species from clinical specimens after alkaline treatment. Acta Pathol. Microbiol. Immunol. Scand. Sect. B. 94:113-116.

148. Peeters, M., and P. Piot. 1985. Adhesion of Gardnerella vaginalis to vaginal epithelial cells: variables affecting adhesion and inhibition by metronidazole. Genitourin. Med. 61: 391-395.

149. Pheifer, T. A., P. S. Forsyth, M. A. Durfee, H. M. Pollock, and K. K. Holmes. 1978. Nonspecific vaginitis: role of Haemophilus vaginalis and treatment with metronidazole. N. Engl. J. Med. 298:1429-1434.

150. Piot, P., and E. van Dyck. 1983. Isolation and identification of Gardnerella vaginalis. Scand. J. Infect. Dis. Suppl. 40:15-18.

151. Piot, P., E. van Dyck, P. Godts, and J. Vanderheyden. 1982. The vaginal microbial flora in nonspecific vaginitis. Eur. J. Clin. Microbiol. 1:301-306.

152. Piot, P., E. van Dyck, P. Godts, and J. Vanderheyden. 1983. A placebo-controlled, double-blind comparison of tinidazole and triple sulfonamide cream for the treatment of nonspecific vaginitis. Am. J. Obstet. Gynecol. 147:85-89.

153. Piot, P., E. van Dyck, M. Goodfellow, and S. Falkow. 1980. A taxonomic study of Gardnerella vaginalis (Haemophilus vaginalis) Gardner and Dukes 1955. J. Gen. Microbiol. 119:373396.

154. Piot, P., E. van Dyck, M. Peeters, J. Hale, P. A. Totten, and K. K. Holmes. 1984. Biotypes of Gardnerella vaginalis. J. Clin. Microbiol. 20:677-679.

155. Piot, P., E. van Dyck, P. A. Totten, and K. K. Holmes. 1982. Identification of Gardnerella (Haemophilus) vaginalis. J. Clin. Microbiol. 15:19-24.

156. Platz-Christensen, J., P. Larsson, E. Sundström, and L. Bondeson. 1989. Detection of bacterial vaginosis in Papanicolaou smears. Am. J. Obstet. Gynecol. 160:132-133.

157. Rabe, L. K., K. K. Winterscheid, and S. L. Hillier. 1988. Association of viridans group streptococci from pregnant women with bacterial vaginosis and upper genital tract infection. J. Clin. Microbiol. 26:1156-1160.

158. Ralph, E. D., and Y. E. Amatnieks. 1980. Relative susceptibilities of Gardnerella vaginalis (Haemophilus vaginalis), Neisseria gonorrhoeae, and Bacteroides fragilis to metronidazole and its two major metabolites. Sex. Transm. Dis. 1:157-160.

159. Redmond, D. L., and E. Kotcher. 1963. Comparison of cultural and immunofluorescent procedures in the identification of Haemophilus vaginalis. J. Gen. Microbiol. 33:89-94.

160. Redondo-Lopez, V., R. L. Cook, and J. D. Sobel. 1990. Emerging role of lactobacilli in the control and maintenance of the vaginal bacterial microflora. Rev. Infect. Dis. 12:856-872.

161. Redondo-Lopez, V., C. Meriwether, C. Schmitt, M. Opitz, R. Cook, and J. D. Sobel. 1990. Vulvovaginal candidiasis complicating recurrent bacterial vaginosis. Sex. Transm. Dis. 17:5153.

162. Reimer, L. G., and L. B. Reller. 1985. Use of polyanethol 
sulfonate disk for the identification of Gardnerella vaginalis. J. Clin. Microbiol. 21:146-149.

163. Rein, M. 1990. Vulvovaginitis and cervicitis, p. 953-964. In G. L. Mandell, R. G. Douglas, and J. E. Bennett (ed.), Principles and practice of infectious diseases, 3rd ed. Churchill Livingstone, New York.

164. Reyn, A., A. Birch-Andersen, and S. P. Lapage. 1966. An electron microscope study of thin sections of Haemophilus vaginalis (Gardner and Dukes) and some possibly related species. Can. J. Microbiol. 12:1125-1136.

165. Roberts, M. C., S. L. Hillier, F. D. Schoenknecht, and K. K. Holmes. 1984. Nitrocellulose filter blots for species identification of Mobiluncus curtisii and Mobiluncus mulieris. J. Clin. Microbiol. 20:826-827.

166. Roberts, M. C., S. L. Hillier, F. D. Schoenknecht, and K. K. Holmes. 1985. Comparison of Gram stain, DNA probe, and culture for the identification of species of Mobiluncus in female genital specimens. J. Infect. Dis. 152:74-77.

167. Rottini, G., A. Dobrina, O. Forgiarini, E. Nardon, G. A. Amirante, and P. Patriarca. 1990. Identification and partial characterization of a cytolytic toxin produced by Gardnerella vaginalis. Infect. Immun. 58:3751-3758.

168. Sadhu, K., P. A. G. Domingue, A. W. Chow, J. Nelligan, N. Cheng, and J. W. Costerton. 1989. Gardnerella vaginalis has a gram-positive cell-wall ultrastructure and lacks classical cellwall lipopolysaccharide. J. Med. Microbiol. 29:229-235.

169. Sanderson, B. E., E. White, and M. J. Balsdon. 1983. Amine content of vaginal fluid from patients with trichomoniasis and gardnerella associated non-specific vaginitis. Br. J. Vener. Dis. 59:302-305.

170. Sautter, R. L., and W. J. Brown. 1980. Sequential vaginal cultures from normal young women. J. Clin. Microbiol. 11: 479-484.

171. Schnadig, V. J., K. D. Davie, S. K. Shafer, R. B. Yandell, M. Z. Islam, and E. V. Hannigan. 1989. The cytologist and bacterial vaginosis of the vaginal-ectocervical area. Acta Cytol. 3:287297.

172. Schröder, R. 1921. Zur Pathogenese und Klinik des vaginalen Fluors. Zentrabl. Gynaekol. 45:1350-1361.

173. Scott, T. G., C. J. Smyth, and C. T. Keane. 1987. In vitro adhesiveness and biotype of Gardnerella vaginalis strains in relation to the occurrence of clue cells in vaginal discharge. Genitourin. Med. 63:47-53.

174. Shah, H. N., and M. D. Collins. 1988. Proposal for reclassification of Bacteroides asaccharolyticus, Bacteroides gingivalis, and Bacteroides endodontalis in a new genus, Porphyromonas. Int. J. Syst. Bacteriol. 38:128-131.

175. Shah, H. N., and M. D. Collins. 1990. Prevotella, a new genus to include Bacteroides melaninogenicus and related species formerly classified in the genus Bacteroides. Int. J. Syst. Bacteriol. 40:205-208.

176. Shaw, C. E., M. E. Forsyth, W. R. Bowie, and W. A. Black. 1981. Rapid presumptive identification of Gardnerella vaginalis (Haemophilus vaginalis) from human blood agar media. J. Clin. Microbiol. 14:108-110.

177. Silva, M., N. V. Jacobus, C. Deneki, and S. L. Gorbach. 1987. Antimicrobial substance from a human lactobacillus strain. Antimicrob. Agents Chemother. 31:1231-1233.

178. Silver, H. M., R. S. Sperling, P. J. St. Clair, and R. S. Gibbs. 1989. Evidence relating bacterial vaginosis to intraamniotic infection. Am. J. Obstet. Gynecol. 161:808-812.

179. Sjöberg, I., and S. Håkansson. 1991. Endotoxin in vaginal fluid of women with bacterial vaginosis. Obstet. Gynecol. 77:265266.

180. Skarin, A., E. Holst, and P.-A. Mårdh. 1983. Antimicrobial susceptibility of comma-shaped bacteria isolated from the vagina. Scand. J. Infect. Dis. Suppl. 40:81-84.

181. Skarin, A., L. Larsson, E. Holst, and P.-A. Mårdh. 1982. Gas chromatographic study of cellular fatty acids of comma-shaped bacteria isolated from the vagina. Eur. J. Clin. Microbiol. 1:307-309.

182. Skarin, A., L. Larsson, E. Holst, and P.-A. Mårdh. 1984. Gas chromatographic analysis of cellular fatty acids in anaerobic curved bacteria isolated from the vagina. Scand. J. Urol. Nephrol. Suppl. 86:71-74.

183. Skarin, A., C. Weibull, and P.-A. Mårdh. 1984. Light and electron microscopic studies of anaerobic curved bacteria isolated from the vagina. Scand. J. Urol. Nephrol. Suppl. 86:59-64.

184. Smith, H., and H. B. Moore. 1988. Isolation of Mobiluncus species from clinical specimens using cold enrichment and selective media. J. Clin. Microbiol. 26:1134-1137.

185. Smith, R. F., H. A. Rodgers, P. A. Hines, and R. M. Ray. 1977. Comparisons between direct microscopic and cultural methods for recognition of Corynebacterium vaginale in women with vaginitis. J. Clin. Microbiol. 5:268-272.

186. Sobel, J. D. 1989. Bacterial vaginosis-an ecologic mystery. Ann. Intern. Med. 111:551-553.

187. Soper, D. E., R. C. Bump, and W. G. Hurt. 1990. Bacterial vaginosis and trichomoniasis vaginitis are risk factors for cuff cellulitis after abdominal hysterectomy. Am. J. Obstet. Gynecol. 163:1016-1023.

188. Spiegel, C. A. Unpublished data.

189. Spiegel, C. A. 1983. Diagnosis of bacterial vaginosis by direct Gram stain of vaginal fluid. J. Clin. Microbiol. 18:170-177.

190. Spiegel, C. A. 1987. Susceptibility of Mobiluncus species to 23 antimicrobial agents and 15 other compounds. Antimicrob. Agents Chemother. 31:249-252.

191. Spiegel, C. A. 1989. Gardnerella vaginalis, p. 1733-1735. In G. L. Mandell, R. G. Douglas, and J. E. Bennett (ed.) Principles and practice of infectious diseases, 3rd ed. Churchill Livingstone, New York.

192. Spiegel, C. A. The genus Mobiluncus, in press. In A. Balows, H. G. Trüper, M. Dworkin, W. Harder, and K. H. Schleifer (ed.), Prokaryotes, 2nd ed. Springer-Verlag, New York.

193. Spiegel, C. A. Vaginitis, in press. In B. W. Wentworth and F. N. Judson (ed.), Laboratory methods for diagnosis of sexually transmitted diseases, 2nd ed. American Public Health Association, Washington, D.C.

194. Spiegel, C. A. June 1989. U.S. patent $4,837,154$.

195. Spiegel, C. A., R. Amsel, D. Eschenbach, F. Schoenknecht, and K. K. Holmes. 1980. Anaerobic bacteria in nonspecific vaginitis. N. Engl. J. Med. 303:601-607.

196. Spiegel, C. A., P. Davick, P. A. Totten, K. C. S. Chen, D. A. Eschenbach, R. Amsel, and K. K. Holmes. 1983. G. vaginalis and anaerobic bacteria in the etiology of bacterial (nonspecific) vaginosis. Scand. J. Infect. Dis. Suppl. 40:41-46.

197. Spiegel, C. A., D. A. Eschenbach, R. Amsel, and K. K. Holmes. 1983. Curved anaerobic bacteria in bacterial (nonspecific) vaginosis and their response to antimicrobial therapy. J. Infect. Dis. 148:817-822.

198. Spiegel, C. A., and K. J. Krueger. 1986. A selective agar for isolation of Mobiluncus from vaginal fluid, abstr. C-334, p. 383. Abstr. 86th Annu. Meet. Am. Soc. Microbiol. 1986. American Society for Microbiology, Washington, D.C.

199. Spiegel, C. A., and M. Roberts. 1984. Mobiluncus gen. nov., Mobiluncus curtisii subspecies curtisii sp. nov., Mobiluncus curtisii subspecies holmesii subsp. nov., and Mobiluncus mulieris sp. nov., curved rods from the human vagina. Int. J. Syst. Bacteriol. 34:177-184.

200. Sprott, M. S., H. R. Ingham, R. S. Pattman, L. M. Clarkson, A. A. Coda, and H. K. Narang. 1984. Motile curved bacilli: isolation and investigation. Scand. J. Urol. Nephrol. Suppl. 86:107-112.

201. Sprott, M. S., H. R. Ingham, R. S. Pattman, R. L. Eisenstadt, G. R. Short, H. K. Narang, P. R. Sisson, and J. B. Selkon. 1983. Characteristics of motile curved rods in vaginal secretions. J. Med. Microbiol. 16:175-182.

202. Steward-Tule, D. E. S. 1964 . Evidence that vaginal lactobacilli do not ferment glycogen. Am. J. Obstet. Gynecol. 88:676-679.

203. Sturm, A. W. 1989. Mobiluncus species and other anaerobic bacteria in non-puerperal breast abscesses. Eur. J. Clin. Microbiol. Infect. Dis. 8:789-792.

204. Sturm, A. W., and P. J. H. Sikkenk. 1984. Anaerobic curved rods in breast abscess. Lancet ii:1216. (Letter.)

205. Svarva, P. L., and J. A. Moeland. 1982. Identification of 
Gardnerella vaginalis by a fluorescent antibody test. Acta Pathol. Microbiol. Immunol. Scand. Sect. B 90:453-455.

206. Tabaqchali, S., M. Wilks, and R. N. Thin. 1983. Gardnerella vaginalis and anaerobic bacteria in genital disease. $\mathrm{Br}$. $\mathrm{J}$. Vener. Dis. 59:111-115.

207. Tashjian, J. H., C. B. Coulam, and J. A. Washington. 1976. Vaginal flora in asymptomatic women. Mayo Clin. Proc. 51:557-561.

208. Taylor, A. J., and R. S. Owens. 1984. Morphological and chemical characteristics of anaerobic curved rod-shaped bacteria from the female genital tract. Scand. J. Urol. Nephrol. Suppl. 86:97-106.

209. Thadepalli, H., W. H. Chan, J. E. Maidman, and E. C. Davidson. 1978. Microflora of the cervix during normal labor and the puerperium. J. Infect. Dis. 137:568-572.

210. Thomason, J. L., S. M. Gelbart, R. J. Anderson, A. K. Walt, P. J. Osypowski, and F. F. Broekhuizen. 1990. Statistical evaluation of diagnostic criteria for bacterial vaginosis. Am. J. Obstet. Gynecol. 162:155-160.

211. Thomason, J. L., S. M. Gelbart, J. A. James, J. M. Edwards, and P. R. Hamilton. 1988. Is analysis of vaginal secretions for volatile organic acids to detect bacterial vaginosis of any diagnostic value? Am. J. Obstet. Gynecol. 159:1509-1511.

212. Thomason, J. L., S. Gelbart, P. J. Osypowski, A. K. Walt, and P. R. Hamilton. 1989. Quality control standards for the proline aminopeptidase assay used to detect bacterial vaginosis. Am. J. Obstet. Gynecol. 160:757-758.

213. Thomason, J. L., S. M. Gelbart, L. M. Wilcoski, A. K. Peterson, B. J. Jilly, and P. R. Hamilton. 1988. Proline aminopeptidase activity as a rapid diagnostic test to confirm bacterial vaginosis. Obstet. Gynecol. 71:607-611.

214. Thomason, J. L., P. C. Schreckenberger, L. J. LeBeau, L. M. Wilcoski, and W. N. Spellacy. 1984. A selective and differential agar for anaerobic comma-shaped bacteria recovered from patients having motile rods and non-specific vaginosis. Scand. J. Urol. Nephrol. Suppl. 86:125-128.

215. Thomason, J. L., P. C. Schreckenberger, W. N. Spellacy, L. J. Riff, and L. J. LeBeau. 1984. Clinical and microbiological characterization of patients with nonspecific vaginosis associated with motile curved anaerobic rods. J. Infect. Dis. 149:801808.

216. Totten, P. A., R. Amsel, J. Hale, P. Piot, and K. K. Holmes. 1982. Selective differential human blood bilayer media for isolation of Gardnerella (Haemophilus) vaginalis. J. Clin. Microbiol. 15:141-147.
217. van der Meijden, W., P. Piot, S. M. Loriaux, and E. Stolz. 1989. Amoxycillin, amoxycillin-clavulanic acid and metronidazole in the treatment of clue cell-positive discharge. A comparative clinical and laboratory study. J. Antimicrob. Chemother. 20: 735-742.

218. van der Meijden, W. I., H. Koerten, W. van Mourik, and W. C. Bruijn. 1988. Descriptive light and electron microscopy of normal and clue cell-positive discharge. Gycecol. Obstet. Invest. 25:47-57.

219. Vejtorp, M., A. C. Bollerup, L. Vejtorp, E. Fanøe, E. Nathan, A. Reller, M. E. Andersen, B. Strømsholt, and S. S. Schrøder. 1988. Bacterial vaginosis: a double-blind randomized trial of the effect of treatment of the sexual partner. Br. J. Obstet. Gynecol. 95:920-926.

220. Vetere, A., S. P. Borriello, E. Fontaine, P. J. Reed, and D. Taylor-Robinson. 1987. Characterisation of anaerobic curved rods (Mobiluncus spp.) isolated from the urogenital tract. J. Med. Microbiol. 23:279-288.

221. Vice, J. L., and M. F. Smaron. 1973. Indirect fluorescentantibody method for the identification of Corynebacterium vaginale. Appl. Microbiol. 25:908-916.

222. Vontver, L. A., and D. A. Eschenbach. 1981. The role of Gardnerella vaginalis in nonspecific vaginitis. Clin. Obstet. Gynecol. 24:439-460.

223. Watts, D. H., D. A. Eschenbach, and G. E. Kenney. 1989. Early postpartum endometritis: the role of bacteria, genital mycoplasmas, and Chlamydia trachomatis. Obstet. Gynecol. 73:5260.

224. Watts, D. H., M. A. Krohn, S. L. Hillier, and D. A. Eschenbach. 1990. Bacterial vaginosis as a risk factor for postcesarean endometritis. Obstet. Gynecol. 75:52-58.

225. Weinbren, M. J., R. M. Perinpanayagam, H. Malnick, and F. Omerod. 1986. Mobiluncus spp.: pathogenic role in non-puerperal breast abscess. J. Clin. Pathol. 39:342-343. (Letter.)

226. Weinstein, L. 1937. The bacterial flora of the human vagina. Yale J. Biol. Med. 10:247-260.

227. Wylie, J. G., and A. Henderson. 1969. Identity and glycogen fermenting activity of lactobacilli isolated from the vagina of pregnant women. J. Med. Microbiol. 2:363-366.

228. Yong, D. C. T., and J. S. Thompson. 1982. Rapid microbiochemical method for identification of Gardnerella (Haemophilus) vaginalis. J. Clin. Microbiol. 16:30-33.

229. Zinneman, K., and G. C. Turner. 1963. The taxonomic position of "Haemophilus vaginalis" (Corynebacterium vaginale). J. Pathol. Bacteriol. 85:213-219. 